Article

\title{
Biobased Polymers via Radical Homopolymerization and Copolymerization of a Series of Terpenoid-Derived Conjugated Dienes with exo-Methylene and 6-Membered Ring
}

\author{
Takenori Nishida ${ }^{1}$, Kotaro Satoh ${ }^{1,2}$ and Masami Kamigaito ${ }^{1, *(D)}$ \\ 1 Department of Molecular and Macromolecular Chemistry, Graduate School of Engineering, \\ Nagoya University, Furo-cho, Chikusa-ku, Nagoya 464-8603, Japan; \\ nishida@chiral.apchem.nagoya-u.ac.jp (T.N.); satoh@cap.mac.titech.ac.jp (K.S.) \\ 2 Department of Chemical Science and Engineering, Tokyo Institute of Technology, School of Materials and \\ Chemical Technology, 2-12-1-H120 Ookayama, Meguro-ku, Tokyo 152-8550, Japan \\ * Correspondence: kamigait@chembio.nagoya-u.ac.jp; Tel.: +81-52-789-5400
}

Academic Editor: Silvia Destri

Received: 9 November 2020; Accepted: 9 December 2020; Published: 12 December 2020

\begin{abstract}
A series of exo-methylene 6-membered ring conjugated dienes, which are directly or indirectly obtained from terpenoids, such as $\beta$-phellandrene, carvone, piperitone, and verbenone, were radically polymerized. Although their radical homopolymerizations were very slow, radical copolymerizations proceeded well with various common vinyl monomers, such as methyl acrylate (MA), acrylonitrile (AN), methyl methacrylate (MMA), and styrene (St), resulting in copolymers with comparable incorporation ratios of bio-based cyclic conjugated monomer units ranging from 40 to $60 \mathrm{~mol} \%$ at a 1:1 feed ratio. The monomer reactivity ratios when using AN as a comonomer were close to 0 , whereas those with St were approximately 0.5 to 1 , indicating that these diene monomers can be considered electron-rich monomers. Reversible addition fragmentation chain-transfer (RAFT) copolymerizations with MA, AN, MMA, and St were all successful when using S-cumyl-S'-butyl trithiocarbonate (CBTC) as the RAFT agent resulting in copolymers with controlled molecular weights. The copolymers obtained with AN, MMA, or St showed glass transition temperatures $\left(T_{\mathrm{g}}\right)$ similar to those of common vinyl polymers $\left(T_{\mathrm{g}} \sim 100^{\circ} \mathrm{C}\right)$, indicating that biobased cyclic structures were successfully incorporated into commodity polymers without losing good thermal properties.
\end{abstract}

Keywords: terpenoid; exo-methylene; conjugated diene; renewable monomer; biobased polymer; radical polymerization; copolymerization; living radical polymerization; RAFT polymerization; heat-resistant polymer

\section{Introduction}

Polymeric materials, such as plastics, rubbers, and fibers, are indispensable products in our daily life and are produced from a variety of low-molecular-weight molecules as building blocks. Radical polymerization is one of the most effective and widely used techniques to produce a wide variety of polymeric materials from various vinyl monomers due to the high reactivity of radical species and its robustness toward polar functional groups in the monomer substituents as well as aqueous compounds in the reaction mixture [1]. In addition, recent progress in controlled/living or reversible deactivation radical polymerization (RDRP) has dramatically expanded the scope of radical polymerization to synthesize precision polymers with various well-defined structures that can be used as high-performance materials [1-10]. 
Sustainable industrial development is now indispensable in view of environmental issues, such as global warming, depletion of fossil resources, and plastic waste. One of the promising solutions to these issues is to use renewable resources, in particular plant-derived molecules, as an alternative to the petroleum-derived monomers for synthetic polymers [11-21]. Moreover, the unique structures of naturally occurring molecules can bestow biobased synthetic polymers with characteristic features that are difficult to attain using simpler petroleum-derived molecules, resulting in novel high-performance materials.

A number of vinyl compounds are produced in nature and are found in a family of abundant natural compounds, such as terpenoids and phenylpropanoids [22-25]. As we have proposed, these biobased vinyl compounds can be classified into similar vinyl monomer families, such as nonpolar olefins, styrenes, and acrylic monomers, to those of petroleum-derived monomers, depending on their substituents and structures [26-29]. For example, renewable polar monomers with conjugated carbonyl groups, such as tulipalin A and itaconic acid, are considered to be acrylic monomers [30-41], whereas phenylpropanoids and their derivatives, such as anethole and vinylguaiacol, are considered to be styrenes [42-48]. These conjugated monomers are generally reactive in radical polymerizations due to the $\mathrm{C}=\mathrm{C}$ bonds conjugated with carbonyl or phenyl groups, resulting in relatively stable propagating radical species.

In contrast, among various terpenes [22-25], the most abundant terpenes are pinene and limonene, which are unconjugated nonpolar olefins without carbonyl or aromatic groups and have difficulty in undergoing radical homopolymerization [49-55]. However, these unconjugated terpenes are radically copolymerized with electron-deficient polar monomers, such as acrylates and maleimides, resulting in biobased copolymers with a relatively high terpene incorporation ratio of up to $50 \mathrm{~mol} \%$. In contrast, a linear conjugated diene, such as myrcene, is another nonpolar olefin terpene and is radically homopolymerized, resulting in rubbery materials [56-62]. However, linear conjugated dienes undergo concurrent Diels-Alder reactions with electron-deficient vinyl monomers via their s-cis forms during radical copolymerization.

Another nonpolar conjugated diene observed in terpenoids is a transoid cyclic conjugated diene with a reactive exo-methylene group, such as $\beta$-phellandrene ( $\beta$-Phe) (Scheme 1). As we briefly reported in a patent [63], $\beta$-Phe possesses high reactivity in cationic polymerization resulting in heat-resistant cycloolefin polymers after subsequent hydrogenation. More recently, we synthesized another exo-methylene 6-membered ring conjugated diene (HCvD: hydrogenated carvone-derived diene) from carvone, which is an abundant naturally occurring $\alpha, \beta$-unsaturated carbonyl compound, via simple chemical transformations consisting of hydrogenation and Wittig reactions [64]. We have also found that HCvD is readily polymerized in cationic polymerization, resulting in alicyclic hydrocarbon polymers with good thermal properties. In addition to HCvD, other exo-methylene transoid 6-membered ring conjugated dienes ( $\mathrm{PtD}$ and $\mathrm{VnD}$ ) have been prepared from a series of naturally occurring $\alpha, \beta$-unsaturated carbonyl compounds, i.e., piperitone and verbenone, respectively, via the Wittig reaction [65].

The exo-methylene-conjugated dienes can be radically homo- and copolymerized with petroleum-derived common vinyl monomers. However, there have been no comprehensive studies on radical homo- and copolymerization of these terpenoid-derived exo-methylene 6-membered ring conjugated dienes except for a few results on the homo- and copolymerizations with some specific monomers, such as styrene, acrylonitrile, and N-phenylmaleimide [65-67]. These results suggest that some of the exo-methylene 6-membered ring conjugated dienes do not seem highly reactive in radical homopolymerization and that they can be copolymerized with electron-deficient monomers. Similar results were reported for 3-methylenecyclopentene, which is an exo-methylene 5-membered ring conjugated diene obtained from the ring-closing metathesis of myrcene $[68,69]$. 
- Renewable Monomers

- exo-Methylene + Conjugated Diene

- Alicyclic 6-Membered Ring
Reactivity

Thermal Properties

RAFT Polymerization
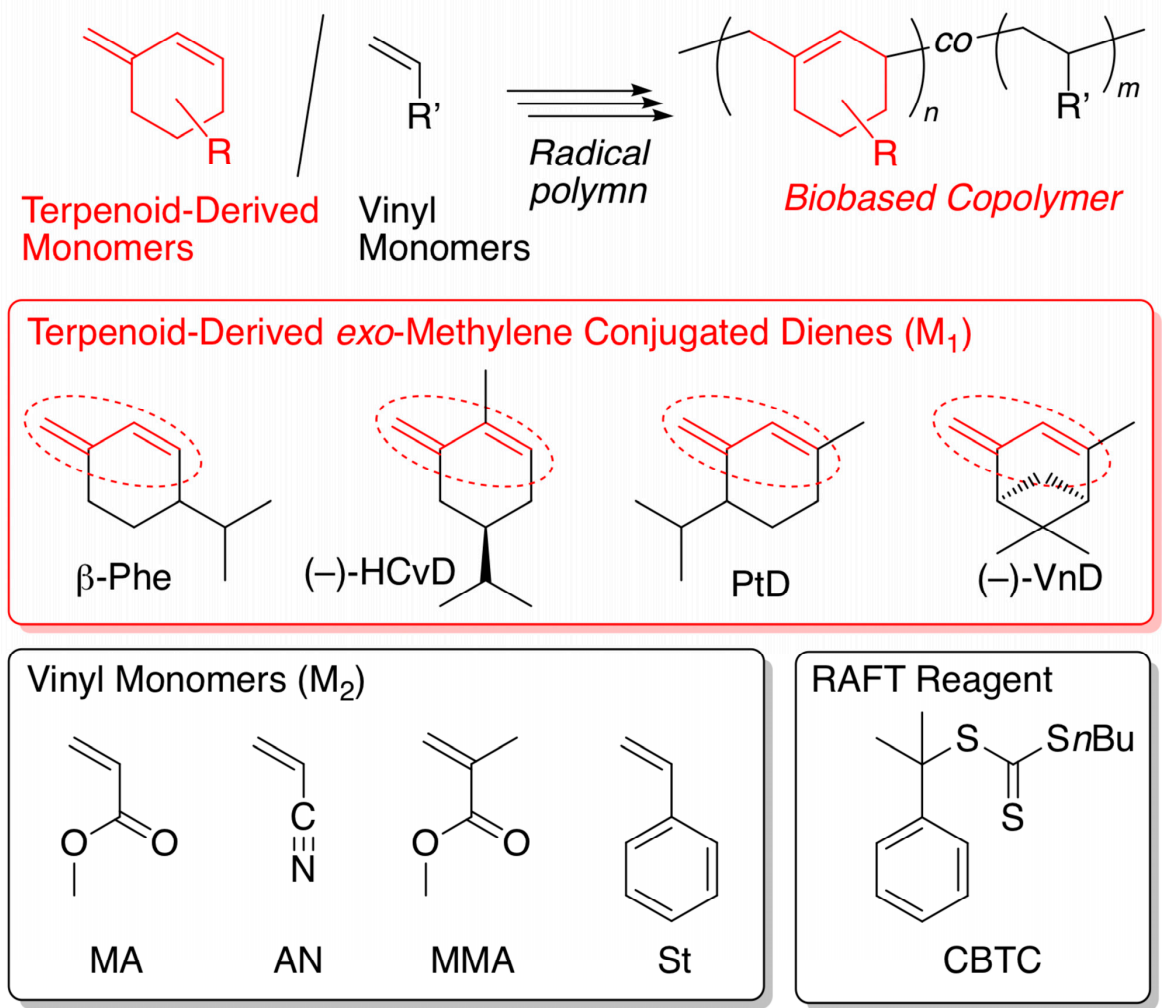

Scheme 1. Radical homo- and copolymerization of a series of terpenoid-derived exo-methylene 6-membered-ring conjugated dienes.

In this work, we fully examined radical homo- and copolymerizations of a series of terpenoid-derived exo-methylene 6-membered ring conjugated dienes ( $\beta$-Phe, $\mathrm{HCvD}, \mathrm{PtD}$, and $\mathrm{VnD})$ using various common vinyl monomers, including methyl acrylate (MA), acrylonitrile (AN), methyl methacrylate (MMA), and styrene (St), as comonomers to evaluate their reactivity in racial polymerization and the thermal properties of the resulting biobased polymers as heat-resistant materials with unique alicyclic skeletons originating from naturally occurring terpenoid molecules.

\section{Results and Discussion}

\subsection{Radical Homopolymerization}

Radical homopolymerizations of a series of terpenoid-derived exo-methylene 6-memered ring conjugated dienes, $\beta-\mathrm{Phe},(-)-\mathrm{HCvD}, \mathrm{PtD}$, and $(-)-\mathrm{VnD}$, which were obtained as previously reported [63,64], were examined in toluene at 60 and $100{ }^{\circ} \mathrm{C}$ using $2,2^{\prime}$-azobisisobutyronitirle (AIBN) and 2,2'-azobis(N-butyl-2-methylpropionamide) (VAm-110), respectively, as radical initiators (Table 1 ). The polymerizations of all monomers at $60{ }^{\circ} \mathrm{C}$ were totally sluggish, resulting in a trace amount of polymers with number-average molecular weights $\left(M_{n}\right)$ less than $10^{4}$. Upon increasing the temperature to $100{ }^{\circ} \mathrm{C}$, although the polymerizations were still slow, they visibly proceeded to result in soluble polymers with relatively high molecular weights $\left(M_{n}>10^{4}\right)$ except for $(-)-\mathrm{VnD}$, which resulted in only low molecular weight oligomers $\left(M_{n}<10^{3}\right)$ at 60 and $100^{\circ} \mathrm{C}$. All size-exclusion chromatography (SEC) curves of the obtained polymers showed unimodal shapes (Figure S1), suggesting that cross-linking reactions with the unconjugated olefins formed in the polymer chains rarely occurred. 
Table 1. Radical polymerization of a series of terpenoid-derived exo-methylene 6-membered ring conjugated dienes ${ }^{a}$.

\begin{tabular}{|c|c|c|c|c|c|c|c|}
\hline Entry & Monomer & Temp. $\left({ }^{\circ} \mathrm{C}\right)$ & Conv. $(\%)^{b}$ & $M_{\mathrm{n}}(\mathrm{SEC})^{c}$ & $M_{\mathrm{w}} / M_{\mathrm{n}}{ }^{c}$ & $1,4-/ 1,2^{d}$ & $T_{\mathrm{g}}\left({ }^{\circ} \mathrm{C}\right)^{e}$ \\
\hline 1 & $\beta$-Phe & 60 & 2 & 3700 & 2.82 & $93 / 7$ & n.d. $f$ \\
\hline 2 & $\beta$-Phe & 100 & 27 & 17,700 & 1.79 & $83 / 17$ & 66 \\
\hline 3 & $\mathrm{HCvD}$ & 60 & 0 & 10,800 & 3.03 & $>99 / 0$ & n.d. $f$ \\
\hline 4 & HCvD & 100 & 32 & 34,400 & 1.89 & $>99 / 0$ & 105 \\
\hline 5 & PtD & 60 & 0 & 3200 & 2.47 & $>99 / 0$ & n.d. $f$ \\
\hline 6 & PtD & 100 & 29 & 10,700 & 1.69 & $>99 / 0$ & 113 \\
\hline 7 & $\mathrm{VnD}$ & 60 & 0 & 240 & 1.10 & n.d. & n.d. $f$ \\
\hline 8 & $\mathrm{VnD}$ & 100 & 2 & 300 & 1.15 & n.d. & n.d. ${ }^{f}$ \\
\hline
\end{tabular}

${ }^{a}$ Polymerization condition: $[\mathrm{M}]_{0} /[\text { radical initiator }]_{0}=5000 / 30 \mathrm{mM}$ in toluene at $60(\mathrm{AIBN})$ or $100{ }^{\circ} \mathrm{C}(\mathrm{VAm}-110)$, reaction time $=280 \mathrm{~h} .{ }^{b}$ Determined by ${ }^{1} \mathrm{H}$ NMR of reaction mixture. ${ }^{c}$ Determined by size-exclusion chromatography (SEC). ${ }^{d}$ Determined by ${ }^{1} \mathrm{H}$ NMR of the obtained polymers. ${ }^{e}$ Determined by DSC. ${ }^{f}$ Not determined.

The ${ }^{1} \mathrm{H}$ NMR spectra of the obtained polymers showed that the polymerization of (-)-HCvD and $\mathrm{PtD}$ proceeded via regioselective 1,4-conjugated addition (Figure 1). There are no olefinic protons at approximately 5-6 ppm for poly((-)-HCvD), whereas no methyl groups attached to olefins were observed at approximately 1.5-2.0 ppm for poly(PtD). Furthermore, for poly $(\mathrm{PtD})$, the peak intensity ratios of methyl protons (0.6-1.0 ppm), which are attached to saturated carbons, to olefin (5.1-5.3 ppm) protons were 8.9:1, indicating not only regioselective 1,4-conjugated addition but also no cross-linking reactions. However, the 1,4-regioselectivity was not complete for poly( $\beta$-Phe), which consisted of 83/17 of 1,4-/1,2-units as estimated from the peak intensity ratios of the olefinic to alkyl protons, in contrast to the complete 1,4-regioselective polymerization of $\beta$-Phe via the cationic mechanism as briefly reported previously [63].

The stereoregularity is another interesting issue of the obtained polymers. The poly((-)-HCvD) obtained via radical polymerization of the chiral monomer was easily soluble in common organic solvents, such as hexane and tetrahydrofuran, whereas an insoluble polymer in these solvents was obtained via the regioselective and stereospecific cationic polymerization of the same chiral monomer [64]. The ${ }^{13} \mathrm{C}$ NMR spectrum of poly $((-)-\mathrm{HCvD})$ obtained via the radical process showed a larger number of peaks than that obtained in the cationic process, in which the chiral center attached to the isopropyl group can dictate the stereospecificity at low temperature (Figure S2).

Thus, both regioselectivity and stereospecificity in the polymerizations of a series of terpenoid-derived exo-methylene conjugated dienes were influenced by the propagating species, among which the radical species resulted in lower selectivities due to the free radical propagating species as well as the higher reaction temperature.

The thermal properties of poly( $\beta$-Phe), poly((-)-HCvD), and poly(PtD) obtained in radical polymerization at $100{ }^{\circ} \mathrm{C}$ were evaluated by differential scanning calorimetry (DSC) (Figure S3). The glass transition temperatures $\left(T_{\mathrm{g}}\right)$ were observed for all polymers. The $T_{\mathrm{g}}$ of poly $((-)-\mathrm{HCvD})$ and poly $(\mathrm{PtD})$ were approximately $110{ }^{\circ} \mathrm{C}$ due to the cyclic structures incorporated into the main chain via regioselective 1,4 -conjugation, whereas the $T_{\mathrm{g}}$ of poly $\left(\beta\right.$-Phe) was $66^{\circ} \mathrm{C}$, which was lower than that of poly $(\beta$-Phe $)\left(T_{\mathrm{g}}=87^{\circ} \mathrm{C}\right)$ obtained in cationic polymerization [63] due to the decreased 1,4-regioselectivity in radical polymerization. In addition, the poly $((-)-\mathrm{HCvD})$ obtained in radical polymerization showed a slightly lower $T_{\mathrm{g}}$ than that obtained in the cationic polymerization of $(-)-H C v D\left(T_{g}=105\right.$ vs. $\left.114^{\circ} \mathrm{C}\right)$ and showed no melting peak due to the lack of stereospecificity in radical polymerization [64].

These results show that a series of the exo-methylene 6-membered ring conjugated dienes are slowly homopolymerized by radical species and that the regioselectivity and stereospecificity are lower for some monomers than those in cationic polymerization. 

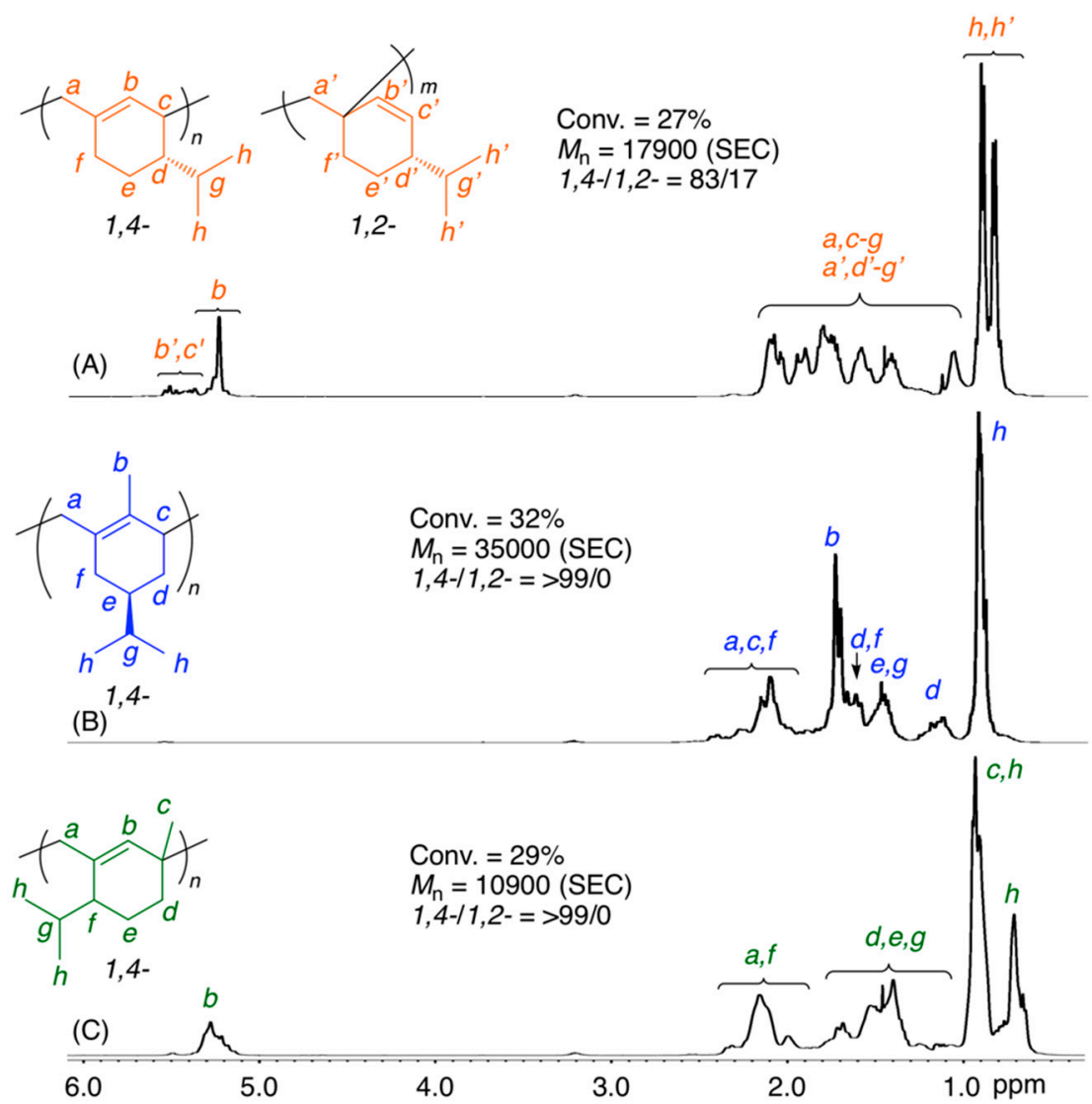

Figure 1. ${ }^{1} \mathrm{H}$ NMR spectra (in $\mathrm{CDCl}_{3}$ at $55{ }^{\circ} \mathrm{C}$ ) of poly( $\beta$-Phe) (A), poly((-)-HCvD) (B), and poly $(\mathrm{PtD})(\mathrm{C})$ obtained in the radical polymerization of the exo-methylene conjugated dienes: $[\mathrm{M}]_{0} /[\mathrm{VAm}-110]_{0}=5000 / 30 \mathrm{mM}$ in toluene at $100{ }^{\circ} \mathrm{C}$.

\subsection{Radical Copolymerization with Various Common Vinyl Monomers}

A series of terpenoid-derived exo-methylene 6-membered ring conjugated dienes were then copolymerized with various common vinyl monomers, such as MA, AN, MMA, and St, at a 1:1 feed ratio in toluene at $60{ }^{\circ} \mathrm{C}$ using AIBN (Figure S4 and Table S1). Radical copolymerizations occurred in almost all cases except for copolymerization with $(-)-\mathrm{VnD}$, in which conversions of both (-)-VnD and comonomers were very low and the obtained products were only oligomers $\left(M_{n} \leq 1 \times 10^{3}\right)$. Therefore, $(-)-\mathrm{VnD}$ is only slightly reactive in radical homo- and copolymerization, probably because the bulky structure with a bicyclic structure and a methyl group at the 4-position makes propagation very difficult in the radical process. Although the other exo-methylene-conjugated dienes were all copolymerized, the reactions at $60^{\circ} \mathrm{C}$ were generally slow and resulted in polymers with relatively low molecular weights $\left(M_{\mathrm{n}}=1 \times 10^{3}-2 \times 10^{4}\right)$.

Therefore, the radical copolymerizations of $\beta$-Phe, $(-)-\mathrm{HCvD}$, and PtD with MA, AN, MMA, and St at a 1:1 feed ratio were investigated at $100{ }^{\circ} \mathrm{C}$ in toluene using VAm-110 as the radical initiator (Table 2 and Figure 2 and Figure S5). The polymerization rates, monomer conversion, and molecular weight of the resulting copolymers $\left(M_{n}=6 \times 10^{3}-4 \times 10^{4}\right)$ were drastically improved, indicating that a higher reaction temperature is favorable for not only homo- but also copolymerization of a series of the exo-methylene 6-membered ring conjugated dienes. 
Table 2. Radical copolymerization of terpenoid-derived exo-methylene 6-membered ring conjugated dienes $\left(\mathrm{M}_{1}\right)$ and various common vinyl monomers $\left(\mathrm{M}_{2}\right)$ in toluene at $100{ }^{\circ} \mathrm{C}$.

\begin{tabular}{|c|c|c|c|c|c|c|c|c|c|c|}
\hline Entry & $\mathbf{M}_{1}$ & $\mathbf{M}_{2}$ & $\begin{array}{c}\text { Time } \\
\text { (h) }\end{array}$ & $\begin{array}{c}\text { Conv.(\%) }^{b} \\
\mathbf{M}_{1} / \mathbf{M}_{2}\end{array}$ & $\begin{array}{c}M_{\mathbf{n}} \\
\left(\mathrm{SEC}^{c}{ }^{c}\right.\end{array}$ & $1,4-/ 1,2-{ }^{d}$ & $\begin{array}{c}\mathbf{M}_{1} / \mathbf{M}_{2} \\
(\mathbf{N M R})^{d}\end{array}$ & $\begin{array}{c}\mathbf{M}_{1} / \mathbf{M}_{2} \\
\text { (Calcd) }^{e}\end{array}$ & $r_{1}^{f}$ & $r_{2} f$ \\
\hline 1 & $\beta$-Phe & MA & 90 & $38 / 27$ & 7900 & $83 / 17$ & $61 / 39$ & $58 / 42$ & 0.66 & 0.04 \\
\hline 2 & HCvD & MA & 20 & $44 / 36$ & 26,000 & $95 / 5$ & $52 / 48$ & $55 / 45$ & 0.14 & 0.08 \\
\hline 3 & $\mathrm{PtD}$ & MA & 20 & $43 / 35$ & 23,800 & $96 / 4$ & $51 / 49$ & $55 / 45$ & 0.11 & 0.08 \\
\hline 4 & $\beta$-Phe & AN & 40 & $51 / 45$ & 14,600 & $84 / 16$ & $52 / 48$ & $53 / 47$ & 0.17 & 0.03 \\
\hline 5 & $\mathrm{HCvD}$ & AN & 10 & $44 / 50$ & 42,100 & $95 / 5$ & $53 / 47$ & $47 / 53$ & 0.09 & 0.03 \\
\hline 6 & $\mathrm{PtD}$ & AN & 10 & $45 / 50$ & 42,300 & $99 / 1$ & $50 / 50$ & $47 / 53$ & 0.02 & 0.05 \\
\hline 7 & $\beta$-Phe & MMA & 150 & $36 / 31$ & 7800 & $89 / 11$ & $60 / 40$ & $54 / 46$ & 0.68 & 0.09 \\
\hline 8 & HCvD & MMA & 50 & $44 / 51$ & 12,900 & $95 / 5$ & $47 / 53$ & $46 / 54$ & 0.17 & 0.31 \\
\hline 9 & $\mathrm{PtD}$ & MMA & 120 & $55 / 62$ & 13,500 & $>99 / 0$ & $46 / 54$ & $47 / 53$ & 0.19 & 0.25 \\
\hline 10 & $\beta$-Phe & St & 120 & $38 / 29$ & 6700 & $85 / 15$ & $60 / 40$ & $57 / 43$ & 1.53 & 0.43 \\
\hline 11 & HCvD & St & 100 & $40 / 54$ & 19,000 & $95 / 5$ & $43 / 57$ & $43 / 57$ & 0.40 & 1.09 \\
\hline 12 & $\mathrm{PtD}$ & St & 50 & $29 / 35$ & 10,900 & $>99 / 0$ & $41 / 59$ & $45 / 55$ & 0.48 & 0.96 \\
\hline
\end{tabular}

${ }^{a}$ Polymerization condition: $\left[\mathrm{M}_{1}\right]_{0} /\left[\mathrm{M}_{2}\right]_{0} /[\mathrm{VAm}-110]_{0}=1500 / 1500 / 30 \mathrm{mM}$ in toluene at $100{ }^{\circ} \mathrm{C} .{ }^{b}$ Determined by ${ }^{1} \mathrm{H}$ NMR of reaction mixture. ${ }^{c}$ Determined by SEC. ${ }^{d}$ Determined by ${ }^{1} \mathrm{H}$ NMR of the obtained polymers. ${ }^{e}$ Determined by the monomer feed ratio and monomer conversion. ${ }^{f}$ Determined by Kelen-Tüdõs method for the copolymerizations at varying monomer feed ratios.
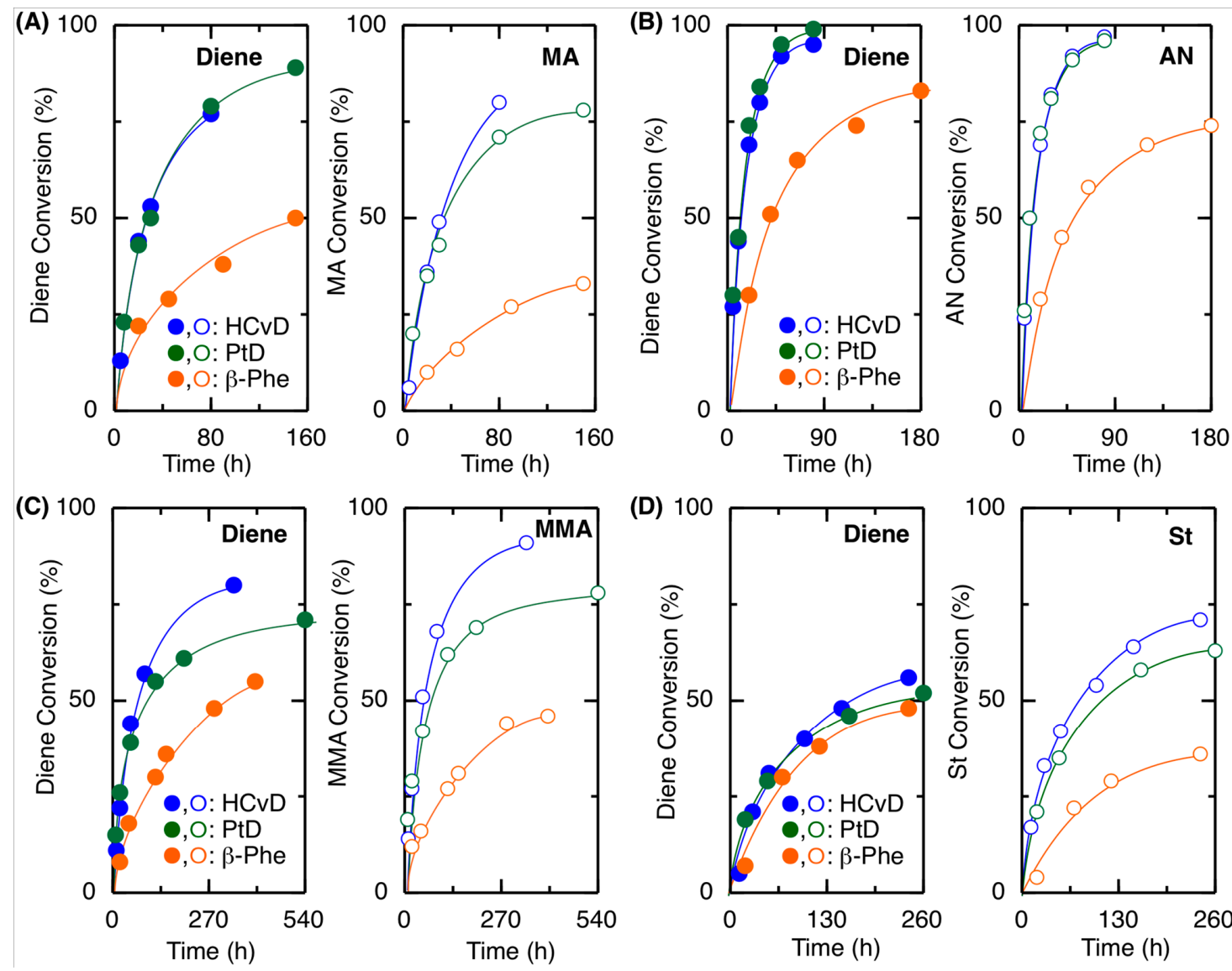

Figure 2. Time-conversion curves for the radical copolymerization of exo-methylene 6-memered-ring conjugated dienes with MA (A), AN (B), MMA (C), or St (D) as a comonomer: $[\text { diene }]_{0} /[\text { comonomer }]_{0} /[\mathrm{VAm}-110]_{0}=1500 / 1500 / 30$ in toluene at $100{ }^{\circ} \mathrm{C}$.

In general, electron-deficient comonomers were suitable for copolymerization, where the reaction rates, conversions, and molecular weights increased in the following order: AN $>$ MA $>$ MMA $>S t$, suggesting that these exo-methylene cyclic conjugated dienes are electron-rich monomers. Among the cyclic conjugated dienes, (-)-HCvD and PtD showed similar reactivities, resulting in polymers with similar molecular weights in all cases, while $\beta$-Phe resulted in slower polymerizations and lower molecular weights. However, the incorporation ratio of $\beta$-Phe was generally greater than that of 
$(-)-H C v D$ and PtD for any comonomer (Table 2). These results suggest that relatively high incorporation of $\beta$-Phe leads to a high probability of the $\beta$-Phe-derived propagating radical species, by which the propagation is slow to result in copolymers with relatively low molecular weights. More details on the monomer reactivity ratio will be studied and discussed in the next section.

All the obtained copolymers were analyzed by ${ }^{1} \mathrm{H}$ NMR to clarify the copolymer structures, particularly regarding the incorporation ratio of comonomers and the regiospecificity of the diene monomers during the copolymerizations (Figure 3, Figures S6-S8). For example, Figure 3 shows spectra of a series of copolymers obtained with $\beta-\mathrm{Phe},(-)-\mathrm{HCvD}$, or PtD and MA. In addition to the characteristic signals of the conjugated diene units, all the spectra showed additional signals of MA units, including not only main-chain methylene and methine protons but also methyl ester protons $(k)$. In particular, olefinic protons $(b)$ were observed at approximately 5-6 ppm for the copolymers of $\beta$-Phe or PtD (Figure 3A,C), although the peaks were slightly broader than those of the homopolymers of $\beta$-Phe or PtD (Figure 1A,C). In addition, almost no olefinic protons were observed for the copolymers of $(-)-H C v D$ (Figure 3B), indicating that the high 1,4-conjugated addition polymerization also proceeded in the copolymerization. For the other various copolymers with AN, MMA, or St (Figures S6-S8), $\beta$-Phe or PtD olefinic protons were similarly observed at approximately $4-6 \mathrm{ppm}$, although the chemical shifts were dependent on the comonomers. Furthermore, for the copolymers of (-)-HCvD with all comonomers, almost no olefinic protons were observed.

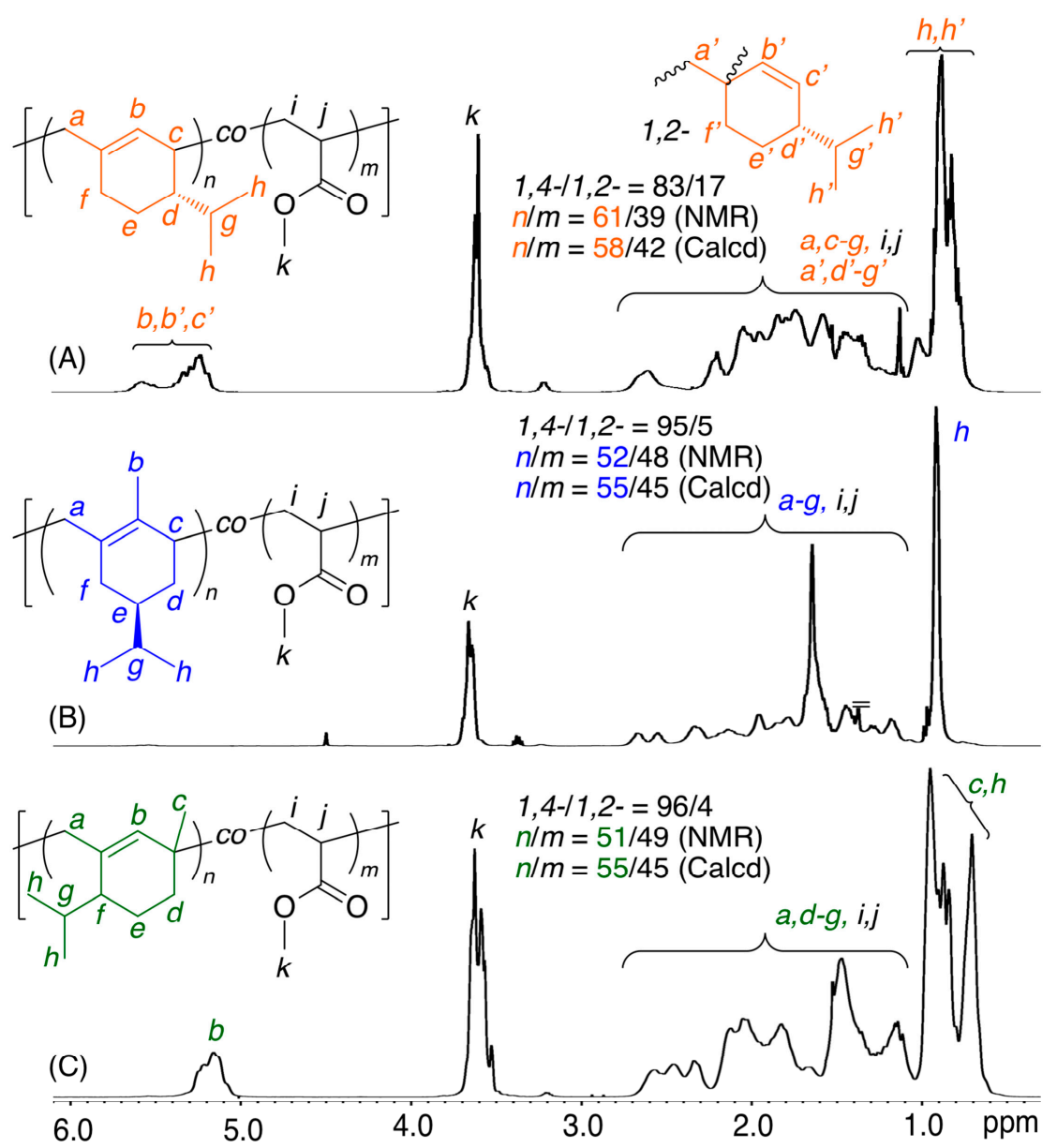

Figure 3. ${ }^{1} \mathrm{H}$ NMR spectra (in $\mathrm{CDCl}_{3}$ at $55^{\circ} \mathrm{C}$ ) of copolymers obtained in the radical copolymerization of $\beta$-Phe (A), (-)-HCvD (B), or PtD (C) with MA: [diene $]_{0} /[\mathrm{MA}]_{0} /[\mathrm{VAm}-110]_{0}=1500 / 1500 / 30 \mathrm{mM}$ in toluene at $100^{\circ} \mathrm{C}$. 
The incorporation ratios of the conjugated dienes $\left(\mathrm{M}_{1}\right)$ and common vinyl monomers $\left(\mathrm{M}_{2}\right)$ were calculated by the peak intensity ratios of the diene and vinyl monomer units in the ${ }^{1} \mathrm{H}$ NMR spectra. The incorporation ratios $\left(\mathrm{M}_{1} / \mathrm{M}_{2}(\mathrm{NMR})\right)$ obtained by NMR of the resulting copolymers were close to the calculated values $\left(\mathrm{M}_{1} / \mathrm{M}_{2}(\mathrm{Calcd})\right)$ based on the feed ratio and monomer conversions, indicating that the consumed monomers were efficiently incorporated into the copolymers. Furthermore, the regioselectivities of the diene units were calculated by the olefinic protons and other protons for all copolymers. The regioselectivities in the copolymers were basically the same as those for the homopolymers. Namely, high 1,4-selectivity was attained for (-)-HCvD and PtD, whereas the 1,4 -selectivity for $\beta$-Phe was approximately $80 \%$.

Thus, a series of terpenoid-derived exo-methylene 6-membered ring conjugated dienes are efficiently copolymerized with various common vinyl monomers, including MA, AN, MMA, and St, via mainly 1,4-conjugated additions resulting in copolymers with biobased monomer incorporation ratios ranging from 40 to $60 \mathrm{~mol} \%$ at a 1:1 feed ratio.

\subsection{Monomer Reactivity Ratio}

To further clarify the copolymerizability of a series of the exo-methylene 6-membered ring conjugated dienes in radical copolymerizations, the monomer reactivity ratios were determined by analyzing the comonomer compositions of the copolymers obtained in the initial stages (total conversion $<10 \%)$ of the copolymerizations at various monomer feed ratios $\left(\left[\mathrm{M}_{1}\right]_{0}+\left[\mathrm{M}_{2}\right]_{0}=5000\right.$ $\mathrm{mM},[\mathrm{VAm}-110]_{0}=30 \mathrm{mM}$ in toluene at $100{ }^{\circ} \mathrm{C}$ ). Figure 4 shows the copolymer composition curves, in which the diene unit content in the resulting copolymers was plotted against the diene content in the monomer feeds. The data were analyzed using the terminal model and were fitted well with the solid lines obtained using the Kelen-Tüdõs method. The obtained $r_{1}$ and $r_{2}$ values are summarized in Table 2.

In general, all the plots and fitted curves for $\mathrm{HCvD}$ and $\mathrm{PtD}$ were close to each other, whereas those for $\beta$-Phe were located above the others, indicating that the incorporation of $\beta$-Phe units in the resulting copolymers was consistently greater than that of $\mathrm{HCvD}$ and $\mathrm{PtD}$ at the same feeds. Correspondingly, the $r_{1}$ values of $\beta$-Phe were consistently larger than those of HCvD and PtD. In addition, the $r_{1}$ values of HCvD and PtD were relatively close. These results indicate that $\mathrm{HCvD}$ and $\mathrm{PtD}$, which both undergo selective 1,4-regioselective propagation, possess similar reactivities, while $\beta$-Phe with a decreased 1,4-regioselectivity shows a higher copolymerizability than HCvD and PtD.

When focusing on the copolymerizations with electron-deficient comonomers (MA, AN, and MMA), both $r_{1}$ and $r_{2}$ were less than 1 , and in particular, those for HCvD and PtD with AN were less than 0.1 , indicating that alternating copolymerization predominantly occurs, as also suggested by the almost constant plot for the various monomer feed ratios (Figure 4B). This is because the exo-methylene-conjugated diene can be considered an electron-rich monomer, whereas AN is the most electron-deficient monomer among the comonomers. For the copolymerizations with St, the sequence of the copolymer is more random because both of the $r$ values are relatively close to 1 , although both monomers are slightly more reactive than the other monomers.

When the $r$ values of the exo-methylene cyclic conjugated dienes are compared with those of a linear conjugated diene, such as butadiene (Bd), they are partially different. The $r_{1}$ values, using $\mathrm{Bd}$ as $\mathrm{M}_{1}$ and the other common vinyl monomers as $\mathrm{M}_{2}$, are 1.09 (MA), 0.36 (AN), 0.75 (MMA), and 1.44 (St) [70], which are greater than those of the exo-methylene cyclic conjugated dienes due to the low homopolymerizability of the exo-methylene cyclic dienes most likely caused by the steric hindrance around the exo-methylene group. In contrast, the $r_{2}$ values for comonomers $\mathrm{M}_{2}$ with $\mathrm{Bd}$ as $\mathrm{M}_{1}$ are 0.07 (MA), $0.05(\mathrm{AN}), 0.25$ (MMA), and $0.84(\mathrm{St})$ [70], which are similar to those obtained in copolymerizations with the exo-methylene cyclic conjugated dienes, indicating that the propagating radical species derived from common comonomers can react with cyclic conjugated dienes with reactivity similar to that of the Bd monomer. 
Thus, a series of terpenoid-derived exo-methylene 6-membered ring conjugated dienes possess sufficiently high copolymerizability with various common vinyl monomers to be efficiently incorporated into the polymer main chains via 1,4-conjugated additions, which results in cyclic structures in the main chain of the copolymers.
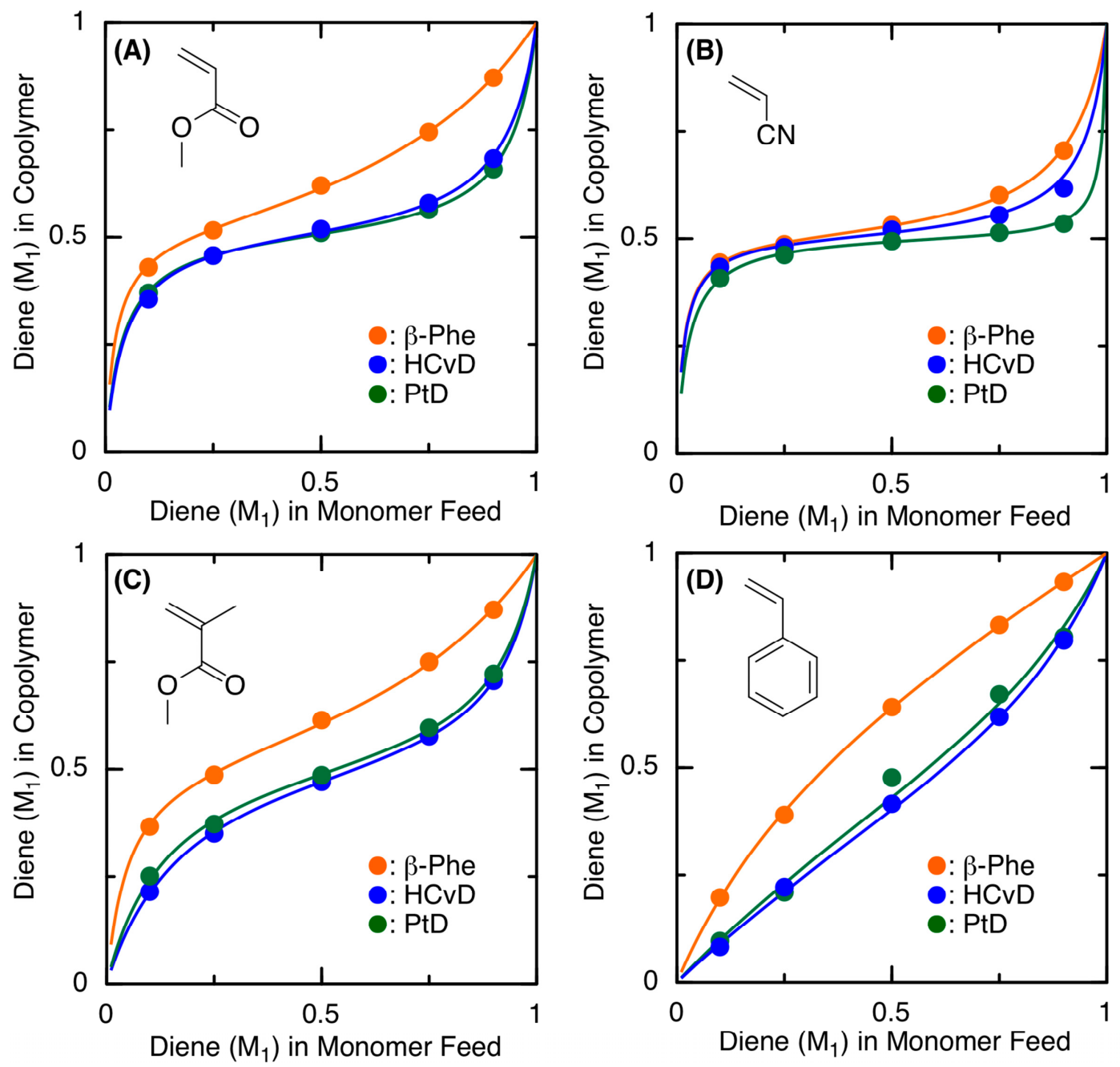

Figure 4. Copolymer composition curves for the radical copolymerization of terpenoid-derived exo-methylene 6-membered-ring conjugated dienes as $\mathrm{M}_{1}$ and MA (A), AN (B), MMA (C), or St (D) as $\mathrm{M}_{2}$ with VAm-110 obtained at varying monomer feed ratios $\left(\left[\mathrm{M}_{1}\right]_{0} /\left[\mathrm{M}_{2}\right]_{0}=1 / 9,1 / 3,1 / 1,3 / 1,9 / 1\right):\left(\left[\mathrm{M}_{1}\right]_{0}\right.$ $\left.+\left[\mathrm{M}_{2}\right]_{0}\right) /[\mathrm{VAm}-110]_{0}=5000 / 30 \mathrm{mM}$ in toluene at $100{ }^{\circ} \mathrm{C}$. The solid lines were fitted by the Kelen-Tüdõs method for the terminal model (see $r_{1}$ and $r_{2}$ values in Table 2).

\subsection{Thermal Properties of Copolymers}

The thermal properties of the various obtained copolymers were evaluated by DSC (Figure 5). All the obtained copolymers showed their characteristic $T_{\mathrm{g}}$ s. For the copolymers of MA, the $T_{\mathrm{g}}$ values were much higher than that of the homopolymer of MA $\left(T_{\mathrm{g}} \sim 10{ }^{\circ} \mathrm{C}\right)$ [70] due to the incorporated terpenoid-derived alicyclic structure, and the $T_{\mathrm{g}}$ values ranged from 50 to $80{ }^{\circ} \mathrm{C}$ depending on the structure of the cyclic conjugated dienes. Furthermore, the $T_{\mathrm{g}}$ values of the copolymers of MMA, $\mathrm{AN}$, and St with (-)-HCvD and $\mathrm{PtD}$ were approximately $100^{\circ} \mathrm{C}$, which is similar to the $T_{\mathrm{g}}$ values of the homopolymers, indicating that the biobased units can be introduced into common vinyl polymers without losing their good thermal properties. This could be a unique benefit of the biobased exo-methylene 6-membered ring conjugated dienes as comonomers for MMA, AN, and St, in contrast 
to linear olefins and dienes, which generally have lower $T_{\mathrm{g}} \mathrm{s}$ due to the soft hydrocarbon units. Thus, terpenoid-derived alicyclic exo-methylene conjugated dienes are promising monomers as novel rigid hydrocarbon units that can be introduced at a high incorporation ratio in radical copolymerization.

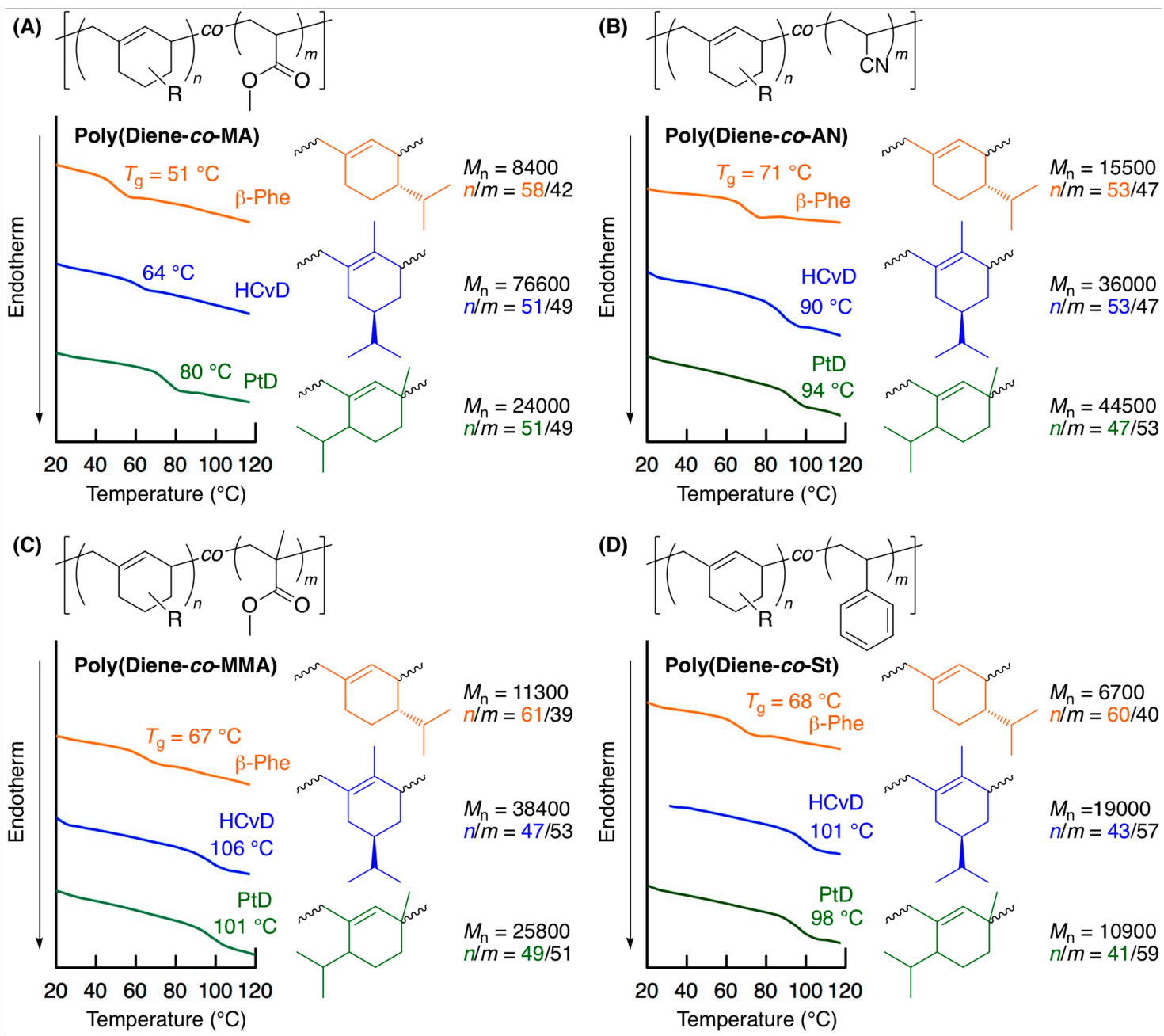

Figure 5. Differential scanning calorimetry (DSC) curves of copolymers obtained in the radical copolymerization of terpenoid-derived exo-methylene 6-membered ring conjugated dienes with MA (A), AN (B), MMA (C), and St (D).

2.5. Reversible Addition Fragmentation Chain-Transfer (RAFT) Copolymerization of (-)-HCvD and Various Common Vinyl Monomers

To control the copolymerization for precision synthesis of the novel biobased polymers, the RAFT copolymerization of (-)-HCvD and various common vinyl monomers (MA, MMA, AN, and St) was investigated at a 1:1 feed ratio using $S$-cumyl-S'-butyl trithiocarbonate (CBTC) as the RAFT agent and VAm-110 as the radical initiator in toluene at $100{ }^{\circ} \mathrm{C}$ (Figure 6 and Figure S9). In all cases, the copolymerizations proceeded smoothly even in the presence of the RAFT agent at conversion ratios similar to those in radical copolymerization without the RAFT agent (Figure S9). 


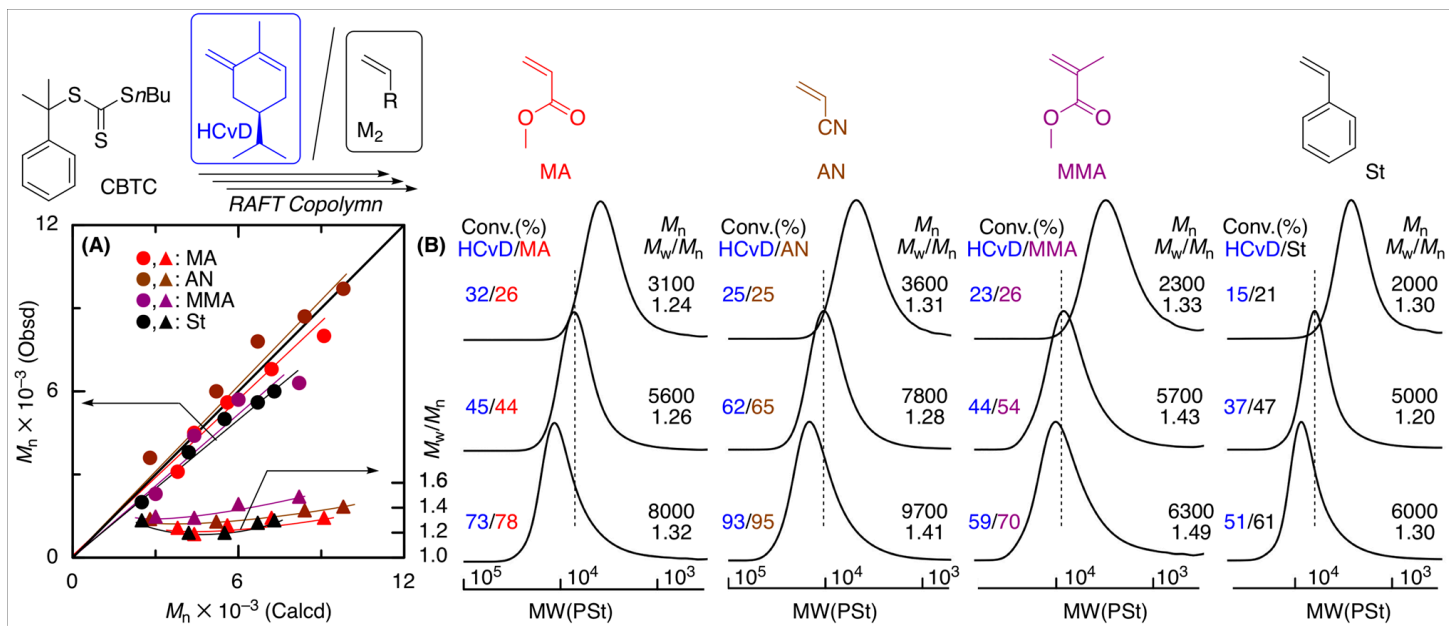

Figure 6. (A) $M_{\mathrm{n}}, M_{\mathrm{w}} / M_{\mathrm{n}}$, and (B) SEC curves of the copolymers obtained in the RAFT copolymerization of $(-)-\mathrm{HCvD}$ with various common vinyl monomers $\left(\mathrm{M}_{2}\right)$ : $[(-)-\mathrm{HCvD}]_{0} /\left[\mathrm{M}_{2}\right]_{0} /[\mathrm{CBTC}]_{0} /[\mathrm{VAm}-110]_{0}=$ $1500 / 1500 / 30 / 10 \mathrm{mM}$ in toluene at $100{ }^{\circ} \mathrm{C}$.

The $M_{\mathrm{n}}$ values of the resulting copolymers increased in direct proportion to total monomer conversion in all cases and were close to the calculated values assuming that one molecule of CBTC generates one polymer chain (Figure 6A). In addition, as the polymerization proceeded, the SEC curves shifted to higher molecular weights while maintaining relatively narrow molecular weight distributions $\left(M_{\mathrm{W}} / M_{\mathrm{n}}=1.2-1.5\right)$ (Figure 6B).

The ${ }^{1} \mathrm{H}$ NMR spectra (Figure S10) of the copolymers obtained in the RAFT copolymerization showed similar large absorptions originating from the terpenoid-based cyclic conjugated dienes and common vinyl monomer units and small signals of both the $\alpha$ - and $\omega$-terminals derived from the RAFT agent, for which signals at 7.3-7.4 and 3.3-3.4 ppm can be attributed to the aromatic and methylene protons originating from CBTC, respectively. The incorporations of (-)-HCvD units into the copolymers were similarly calculated by the peak intensity ratios and were almost the same as those for the copolymers obtained in radical copolymerization without the RAFT agent. The $M_{n}$ values calculated from the peak intensity ratios of the $\alpha$ - and $\omega$-RAFT terminals to the repeating units were close to both $M_{\mathrm{n}}(\mathrm{SEC})$ and $M_{\mathrm{n}}(\mathrm{Calcd})$, suggesting that one CBTC molecule generates one polymer chain. These results indicate that CBTC is suitable for controlling the RAFT copolymerization of (-)-HCvD and various common vinyl monomers to produce copolymers with controlled molecular weights and chain-end groups, which can be used for synthesis of the novel biobased functional polymers.

\section{Materials and Methods}

\subsection{Materials}

Toluene (KANTO, $>99.5 \% ; \mathrm{H}_{2} \mathrm{O}<10 \mathrm{ppm}$ ) and tetrahydrofuran (THF) (KANTO, $>99.5 \%$; $\mathrm{H}_{2} \mathrm{O}<0.001 \%$ ) was dried and deoxygenized by passage through Glass Contour Solvent Systems columns before use. (Methyl)triphenylphosphonium bromide (KANTO, >98\%) and potassium tert-butoxide (Tokyo Chemical Industry, $>97 \%$ ) were used as received. Piperitone (mixture of enantiomers, predominantly ( $R$ )-form, Tokyo Chemical Industry, $>94 \%$ ), angelica seed oil (Aldrich, containing approximately $80 \% \beta$-phellandrene), methyl acrylate (MA) (Tokyo Chemical Industry, $>99 \%$ ), acrylonitrile (AN) (Tokyo Chemical Industry, >99\%), methyl methacrylate (MMA) (Tokyo Chemical Industry, >98\%), styrene (St) (Kishida, 99.5\%), and 1,2,3,4-tetrahydronaphthalene (Wako, 97\%) were distilled under reduced pressure before use. (-)-Verbenone (Tokyo Chemical Industry, $>95 \%$ ) was purified by column chromatography on silica gel with $n$-hexane/ethyl acetate (6/4) as the eluent to result in the pure compound (>99\%). N-Cyclohexylmaleimide (Aldrich, 97\%) was purified by recrystallization from toluene. 2,2'-Azobisisobutyronitirle (AIBN) (Kishida, >99\%) and 
2,2'-azobis( $N$-butyl-2-methylpropionamide) (VAm-110) (Wako, $>95 \%$ ) were purified by recrystallization from methanol and hexane. (-)-HCvD [63] and S-cumyl-S'-butyl trithiocarbonate (CBTC) [71] were synthesized according to the literature.

\subsection{Purification of $\beta$-Phellandrene ( $\beta$-Phe)}

$\beta$-Phellandrene ( $\beta$-Phe) was obtained from angelica seed oil. $N$-Cyclohexylmaleimide $(24.3 \mathrm{~g}, 0.14$ mol) was added to distilled angelica seed oil $(75.9 \mathrm{~g})$, which contained $\beta$-Phe $(92 \%)$ and a small amount of linear and cisoid-conjugated dienes, such as myrcene and $\alpha$-phellandrene as impurities, and the linear and cisoid compounds were removed using the Diels-Alder reaction. The reaction mixture was stirred at $90^{\circ} \mathrm{C}$ for $1 \mathrm{~h}$. After cooling the reaction mixture to $0{ }^{\circ} \mathrm{C}$ for quenching, the crude product was purified by column chromatography on silica gel with $n$-hexane as the eluent to yield $\beta$-Phe with a higher purity $(27 \mathrm{~g}, 35 \%$ yield, $99 \%$ purity). Further purification was conducted by distillation to produce a colorless $\beta$-Phe oil ( $14 \mathrm{~g}, 19 \%$ yield, $>99 \%$ purity, bp $\left.65^{\circ} \mathrm{C} / 2700 \mathrm{~Pa} .[\alpha]_{\mathrm{D}}{ }^{25}=+27^{\circ}\right)$.

\subsection{Synthesis of (-)-VnD}

$(-)-\mathrm{VnD}$ was prepared by the Wittig reaction of purified (-)-verbenone. (Methyl)triphenylphosphonium bromide (140.2 g, $0.392 \mathrm{~mol}$ ) was suspended in dry THF $(700 \mathrm{~mL})$ at $0{ }^{\circ} \mathrm{C}$ in a three-necked $2 \mathrm{~L}$ round-bottom flask equipped with three-way stopcocks. Potassium tert-butoxide $(44.1 \mathrm{~g}, 0.392 \mathrm{~mol})$ was added resulting in a yellow suspension. After $30 \mathrm{~min}$, (-)-verbenone $(40 \mathrm{~mL}, 0.261 \mathrm{~mol})$ was added to the yellow suspension resulting in an orange product, and the reaction mixture was stirred at room temperature. After $16 \mathrm{~h}$, the conversion of verbenone reached $>99 \%$ by ${ }^{1} \mathrm{H}$ NMR. Then, water $(400 \mathrm{~mL})$ was added to quench the reaction. The organic layer was concentrated by rotary evaporation. Hexane $(300 \mathrm{~mL})$ was added to the obtained residue. After the mixture was filtered to remove the precipitated triphenylphosphine oxide, the obtained solution was concentrated. The obtained residue was similarly treated again to yield the crude $(-)-V n D$ product ( $32.1 \mathrm{~g}, 82 \%$ yield). Further purification was conducted by distillation to produce a colorless oil of pure $(-)-\mathrm{VnD}\left(28.9 \mathrm{~g}, 74 \%\right.$ yield, $>99 \%$ purity, bp $\left.55^{\circ} \mathrm{C} / 1600 \mathrm{~Pa},[\alpha]_{\mathrm{D}}^{25}=-44^{\circ}\right)$. ${ }^{1} \mathrm{H}$ NMR $\left(\mathrm{CDCl}_{3}\right.$, r.t.): $\delta 0.82\left(\mathrm{~s}, 3 \mathrm{H}, \mathrm{CH}_{3}\right), 1.35\left(\mathrm{~s}, 3 \mathrm{H}, \mathrm{CH}_{3}\right), 1.43-1,46\left(\mathrm{~d}, 1 \mathrm{H}, \mathrm{CH}_{2}\right), 1.78(\mathrm{~s}, 3 \mathrm{H}$, $\left.\mathrm{CH}_{2}=\mathrm{C}-\mathrm{CH}=\mathrm{C}-\mathrm{CH}_{3}\right), 2.09-2.12\left(\mathrm{t}, 1 \mathrm{H}, \mathrm{CH}_{2}=\mathrm{C}-\mathrm{CH}=\mathrm{C}-\mathrm{CH}\right), 2.48-2.53\left(\mathrm{~m}, 1 \mathrm{H}, \mathrm{CH}_{2}\right), 2.58-2.61(\mathrm{~s}, 1 \mathrm{H}$, $\left.\mathrm{CH}_{2}=\mathrm{C}(\mathrm{CH})-\mathrm{CH}=\mathrm{C}\right), 4.56\left(\mathrm{~s}, 2 \mathrm{H}, \mathrm{CH}_{2}=\mathrm{C}-\mathrm{CH}=\mathrm{C}\right), 5.77\left(\mathrm{~s}, 1 \mathrm{H}, \mathrm{CH}_{2}=\mathrm{C}-\mathrm{CH}=\mathrm{C}\right) .{ }^{13} \mathrm{C} \mathrm{NMR}\left(\mathrm{CDCl}_{3}\right.$, r.t.): $\delta$

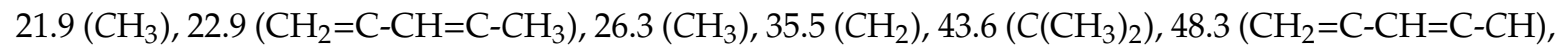
$51.4\left(\mathrm{CH}_{2}=\mathrm{C}(\mathrm{CH})-\mathrm{CH}=\mathrm{C}\right), 104.9\left(\mathrm{CH}_{2}=\mathrm{C}-\mathrm{CH}=\mathrm{C}\right), 121.0\left(\mathrm{CH}_{2}=\mathrm{C}-\mathrm{CH}=\mathrm{C}\right), 147.8\left(\mathrm{CH}_{2}=\mathrm{C}-\mathrm{CH}=\mathrm{C}\right), 149.7$ $\left(\mathrm{CH}_{2}=\mathrm{C}-\mathrm{CH}=\mathrm{C}\right) .{ }^{1} \mathrm{H},{ }^{13} \mathrm{C}, \mathrm{COSY}$, and HMQC NMR spectra are shown in Figures S11-S13.

\subsection{Synthesis of PtD}

$\mathrm{PtD}$ was prepared by the Wittig reaction of distilled piperitone. (Methyl)triphenylphosphonium bromide $(131.6 \mathrm{~g}, 0.369 \mathrm{~mol})$ was suspended in dry THF $(700 \mathrm{~mL})$ at $0{ }^{\circ} \mathrm{C}$ in a three-necked $2 \mathrm{~L}$ round-bottom flask equipped with three-way stopcocks. Potassium tert-butoxide ( $41.3 \mathrm{~g}, 0.369 \mathrm{~mol})$ was added to the suspension resulting in a yellow suspension. After $30 \mathrm{~min}$, piperitone $(40 \mathrm{~mL}, 0.246$ mol) was added to the yellow suspension to produce an orange product, and the reaction mixture was stirred at room temperature. After $16 \mathrm{~h}$, the conversion of piperitone reached $>99 \%$ by ${ }^{1} \mathrm{H} N \mathrm{NMR}$. Then, water $(400 \mathrm{~mL})$ was added to quench the reaction. The organic layer was concentrated by rotary evaporation. Hexane $(300 \mathrm{~mL})$ was added to the obtained residue. After the mixture was filtered to remove the precipitated triphenylphosphine oxide, the obtained solution was concentrated. The crude product after the Wittig reaction ( $30.3 \mathrm{~g}, 82 \%$ yield, $81 \%$ purity) was purified by column chromatography on silica gel with $n$-hexane as the eluent to yield the product with a higher purity ( $19.9 \mathrm{~g}, 36 \%$ yield, 94\% purity). Further purification was conducted by distillation to produce the colorless PtD oil $\left(16.1 \mathrm{~g}, 29 \%\right.$ yield, $95 \%$ purity, bp $\left.70{ }^{\circ} \mathrm{C} / 1600 \mathrm{~Pa},[\alpha]_{\mathrm{D}}{ }^{25}=+16^{\circ}\right) .{ }^{1} \mathrm{H} \mathrm{NMR}\left(\mathrm{CDCl}_{3}\right.$, r.t.): $\delta 0.88-0.92\left(\mathrm{dd}, 6 \mathrm{H}, \mathrm{cy}-\mathrm{CH}\left(\mathrm{CH}_{3}\right)_{2}\right), 1.62-1.71\left(\mathrm{~m}, 2 \mathrm{H}, \mathrm{CH}(\mathrm{iPr})-\mathrm{CH}_{2}-\mathrm{CH}_{2}, \mathrm{cy}-\mathrm{CH}\left(\mathrm{CH}_{3}\right)_{2}\right), 1.73$ (s, $\left.3 \mathrm{H}, \mathrm{CH}_{2}=\mathrm{C}-\mathrm{CH}=\mathrm{C}-\mathrm{CH}_{3}\right), 1.78-1.94\left(\mathrm{~m}, 3 \mathrm{H}, \mathrm{CH}(\mathrm{iPr})-\mathrm{CH}_{2}-\mathrm{CH}_{2}, \mathrm{CH}(\mathrm{iPr})-\mathrm{CH}_{2}-\mathrm{CH}_{2}, \mathrm{CH}(\mathrm{iPr})-\mathrm{CH}_{2}-\mathrm{CH}_{2}\right)$, 
2.03-2.19 (m, 1H, $\left.\mathrm{CH}(\mathrm{iPr})-\mathrm{CH}_{2}-\mathrm{CH}_{2}\right), 4.63\left(\mathrm{~s}, 1 \mathrm{H}\right.$, trans, $\left.\mathrm{CH}_{2}=\mathrm{C}-\mathrm{CH}=\mathrm{C}\right), 4.74\left(\mathrm{~s}, 1 \mathrm{H}\right.$, cis, $\left.\mathrm{CH}_{2}=\mathrm{C}-\mathrm{CH}=\mathrm{C}\right)$, 5.85 (s, $\left.1 \mathrm{H}, \mathrm{CH}_{2}=\mathrm{C}-\mathrm{CH}=\mathrm{C}\right) .{ }^{13} \mathrm{C}$ NMR $\left(\mathrm{CDCl}_{3}\right.$, r.t.): $\delta 19.9\left(\mathrm{cy}-\mathrm{CH}\left(\mathrm{CH}_{3}\right)_{2}\right), 21.9\left(\mathrm{cy}-\mathrm{CH}\left(\mathrm{CH}_{3}\right)_{2}\right)$, $23.6\left(\mathrm{CH}_{2}=\mathrm{C}-\mathrm{CH}=\mathrm{C}-\mathrm{CH}_{3}\right), 24.7\left(\mathrm{CH}(i \mathrm{Pr})-\mathrm{CH}_{2}-\mathrm{CH}_{2}\right), 27.0\left(\mathrm{cy}-\mathrm{CH}\left(\mathrm{CH}_{3}\right)_{2}\right), 27.7\left(\mathrm{CH}(i \mathrm{Pr})-\mathrm{CH}_{2}-\mathrm{CH}_{2}\right)$, $46.2\left(\mathrm{CH}(\mathrm{iPr})-\mathrm{CH}_{2}-\mathrm{CH}_{2}\right), 109.4\left(\mathrm{CH}_{2}=\mathrm{C}-\mathrm{CH}=\mathrm{C}\right), 125.1\left(\mathrm{CH}_{2}=\mathrm{C}-\mathrm{CH}=\mathrm{C}\right), 137.6\left(\mathrm{CH}_{2}=\mathrm{C}-\mathrm{CH}=\mathrm{C}\right), 146.4$ $\left(\mathrm{CH}_{2}=\mathrm{C}-\mathrm{CH}=\mathrm{C}\right) .{ }^{1} \mathrm{H},{ }^{13} \mathrm{C}, \mathrm{COSY}$, and HMQC NMR spectra are shown in Figures S11, S14, and S15.

\subsection{RAFT Copolymerization}

RAFT copolymerization was carried out using the syringe technique under dry nitrogen in sealed glass tubes. A typical example for (-)-HCvD and MA copolymerization with CBTC and VAm-110 in toluene is given below. (-)-HCvD $(0.60 \mathrm{~mL}, 3.3 \mathrm{mmol})$, MA $(0.30 \mathrm{~mL}, 3.3 \mathrm{mmol}), \mathrm{CBTC}(0.13 \mathrm{~mL}$, $508 \mathrm{mM}$ solution in toluene, $0.066 \mathrm{mmol})$, and VAm-110 $(1.19 \mathrm{~mL}$ of $18.6 \mathrm{mM}$ solution in toluene, $0.022 \mathrm{mmol}$ ) were placed in a baked $25 \mathrm{~mL}$ graduated Schlenk flask equipped with a three-way stopcock at room temperature. The total volume of the reaction mixture was $2.2 \mathrm{~mL}$. Immediately after mixing, aliquots $(0.4 \mathrm{~mL}$ each) of the solution were distributed via syringe into baked glass tubes, which were then sealed by flame in a nitrogen atmosphere. The tubes were immersed in a thermostatic oil bath at $100{ }^{\circ} \mathrm{C}$. At predetermined intervals, the polymerization was terminated by cooling the reaction mixtures to $-78{ }^{\circ} \mathrm{C}$. The monomer conversion was determined from the concentration of residual monomer measured by ${ }^{1} \mathrm{H}$ NMR with toluene as an internal standard $(20 \mathrm{~h}, 32 \%$ for $(-)-\mathrm{HCvD}$ and $26 \%$ for MA). The quenched reaction solutions were evaporated to dryness to give the product copolymer $\left(M_{\mathrm{n}}=3100, M_{\mathrm{w}} / M_{\mathrm{n}}=1.24\right)$.

\subsection{Measurements}

The ${ }^{1} \mathrm{H}$ NMR spectra for the monomer conversion and product polymer were recorded on a JEOL ECS-400 spectrometer operating at $400 \mathrm{MHz}$. The number-average molecular weight $\left(M_{\mathrm{n}}\right)$ and molecular weight distribution $\left(M_{\mathrm{w}} / M_{\mathrm{n}}\right)$ of the product polymer were determined by SEC in THF at $40{ }^{\circ} \mathrm{C}$ on two polystyrene gel columns (Tosoh Multipore $\mathrm{H}_{\mathrm{xL}}-\mathrm{M}(7.8 \mathrm{~mm}$ i.d. $\times 30 \mathrm{~cm}) \times$ 2; flow rate: $1.0 \mathrm{~mL} / \mathrm{min}$ ) connected to a JASCO PU-2080 precision pump and a JASCO RI-2031 detector. The columns were calibrated with standard polystyrene samples (Agilent Technologies; $\left.M_{\mathrm{p}}=580-3,242,000, M_{\mathrm{w}} / M_{\mathrm{n}}=1.02-1.23\right)$. The glass transition temperature $\left(T_{\mathrm{g}}\right)$ of the polymers was recorded on a Q200 differential scanning calorimeter (TA Instruments, Inc.). Samples were first heated to $150{ }^{\circ} \mathrm{C}$ at $10{ }^{\circ} \mathrm{C} / \mathrm{min}$, equilibrated at this temperature for $10 \mathrm{~min}$, and cooled to $0{ }^{\circ} \mathrm{C}$ at $5{ }^{\circ} \mathrm{C} / \mathrm{min}$. After being held at this temperature for $5 \mathrm{~min}$, the samples were then reheated to $200^{\circ} \mathrm{C}$ at $10^{\circ} \mathrm{C} / \mathrm{min}$. All $T_{\mathrm{g}}$ values were obtained from the second scan after removing the thermal history.

\section{Conclusions}

In conclusion, radical polymerizations of a series of terpenoid-derived exo-methylene 6-membered ring conjugated dienes were investigated with the aim of developing novel biobased polymeric materials. Although their reactivities for homopolymerization in radical processes were lower than those in cationic processes, copolymerizations with various common vinyl monomers efficiently occurred, resulting in unique biobased copolymers. The substituents on the 6-membered ring of exo-methylene conjugated dienes affected the regiospecificity and monomer reactivity. The obtained copolymers contained relatively high biobased units, ranging from 40 to $60 \mathrm{~mol} \%$ even at a $1: 1$ feed ratio, and the glass transition temperatures were comparable to those of the homopolymers obtained from common vinyl monomers. In addition, biobased units can be incorporated into copolymers in a controlled fashion via the RAFT process. We believe that these exo-methylene-conjugated dienes can be new building blocks to synthesize copolymers with terpenoid-derived alicyclic structures, which serve as hydrocarbon units with good thermal properties. 
Supplementary Materials: The following are available online Figure S1. SEC curves of the homopolymers obtained in the radical polymerization of $\beta-\mathrm{Phe},(-)-\mathrm{HCvD}$, and PtD: $[\mathrm{M}]_{0} /[\mathrm{VAm}-110]_{0}=5000 / 30 \mathrm{mM}$ in toluene at $100{ }^{\circ} \mathrm{C}$; Figure S2. ${ }^{13} \mathrm{C}$ NMR spectra (in $\mathrm{C}_{2} \mathrm{D}_{2} \mathrm{Cl}_{4}$ at $100{ }^{\circ} \mathrm{C}$ ) of poly((-)-HCvD) obtained in the cationic (A) and radical (B) polymerization: $[(-)-\mathrm{HCVD}]_{0} /[\mathrm{CEVE}-\mathrm{HCl}]_{0} /\left[\mathrm{SnCl}_{4}\right]_{0} /\left[\mathrm{nBu}_{4} \mathrm{NCl}\right]_{0}=100 / 1.0 / 5.0 / 4.0 \mathrm{mM}$ in toluene/ $/ \mathrm{CH}_{2} \mathrm{Cl}_{2}(50 / 50 \mathrm{vol} \%)$ at $-78{ }^{\circ} \mathrm{C}\left(M_{\mathrm{n}}(\mathrm{Calcd})=15,200\right)(\mathrm{A})$ or $[(-)-\mathrm{HCvD}]_{0} /[\mathrm{VAm}-110]_{0}=5000 / 30 \mathrm{mM}$ in toluene at $100{ }^{\circ} \mathrm{C}(\mathrm{B})$; Figure S3. Differential scanning calorimetry (DSC) curves of poly $(\beta-\mathrm{Phe})$, poly $((-)-\mathrm{HCvD})$, and poly $(\mathrm{PtD})$ obtained in the radical polymerization: $[\mathrm{M}]_{0} /[\mathrm{VAm}-110]_{0}=5000 / 30 \mathrm{mM}$ in toluene at $100{ }^{\circ} \mathrm{C}$; Figure $\mathrm{S} 4$. Time-conversion curves for the radical copolymerization of terpenoid-derived exo-methylene 6-membered ring conjugated dienes with MA (A), AN (B), MMA (C), and St (D) as a comonomer: [diene $]_{0} /[\text { comonomer }]_{0} /[\mathrm{AIBN}]_{0}=1500 / 1500 / 30 \mathrm{mM}$ in toluene at $60^{\circ} \mathrm{C}$; Figure S5. SEC curves of the copolymers obtained in the radical copolymerization of terpenoid-derived exo-methylene 6-membered-ring conjugated dienes $\left(\mathrm{M}_{1}\right)$ with various common vinyl monomers $\left(\mathrm{M}_{2}\right):\left[\mathrm{M}_{1}\right]_{0} /\left[\mathrm{M}_{2}\right]_{0} /[\mathrm{VAm}-110]_{0}=$ $1500 / 1500 / 30 \mathrm{mM}$ in toluene at $100{ }^{\circ} \mathrm{C}$; Figure $\mathrm{S} 6 .{ }^{1} \mathrm{H}$ NMR spectra (in $\mathrm{CDCl}_{3}$ at $55^{\circ} \mathrm{C}$ ) of copolymers obtained in the radical copolymerization of $\beta$-Phe (A), $(-)-\mathrm{HCvD}(\mathrm{B})$, or PtD (C) with $\mathrm{AN}$ : [diene $]_{0} /[\mathrm{AN}]_{0} /[\mathrm{VAm}-110]_{0}=1500 / 1500 / 30$ $\mathrm{mM}$ in toluene at $100{ }^{\circ} \mathrm{C}$; Figure S7. ${ }^{1} \mathrm{H}$ NMR spectra (in $\mathrm{CDCl}_{3}$ at $55{ }^{\circ} \mathrm{C}$ ) of copolymers obtained in the radical copolymerization of $\beta$-Phe (A), (-)-HCvD (B), or PtD (C) with MMA: [diene $]_{0} /[\mathrm{MMA}]_{0} /[\mathrm{VAm}-110]_{0}=1500 / 1500 / 30$ $\mathrm{mM}$ in toluene at $100{ }^{\circ} \mathrm{C}$; Figure S8. ${ }^{1} \mathrm{H}$ NMR spectra (in $\mathrm{CDCl}_{3}$ at $55{ }^{\circ} \mathrm{C}$ ) of copolymers obtained in the radical copolymerization of $\beta$-Phe (A), (-)-HCvD (B), or PtD (C) with St: [diene $]_{0} /[\mathrm{St}]_{0} /[\mathrm{VAm}-110]_{0}=1500 / 1500 / 30 \mathrm{mM}$ in toluene at $100{ }^{\circ} \mathrm{C}$; Figure S9. Time-conversion curves for the RAFT copolymerization of (-)-HCvD with MA (A), AN (B), MMA $(\mathrm{C})$, and St (D) as a comonomer: $[(-)-\mathrm{HCvD}]_{0} /[\text { comonomer }]_{0} /[\mathrm{CBTC}]_{0} /[\mathrm{VAm}-110]_{0}=1500 / 1500 / 30 / 10 \mathrm{mM}$ in toluene at $100{ }^{\circ} \mathrm{C}$; Figure S10. ${ }^{1} \mathrm{H}$ NMR spectra (in $\mathrm{CDCl}_{3}$ at $55^{\circ} \mathrm{C}$ ) of copolymers obtained in the RAFT copolymerization of (-)-HCvD with MA (A), AN (B), MMA (C), or St (D) as a comonomer: [(-)-HCvD $]_{0} /[\text { comonomer }]_{0} /[\mathrm{CBTC}]_{0} /[\mathrm{VAm}-110]_{0}$ $=1500 / 1500 / 30 / 10 \mathrm{mM}$ in toluene at $100{ }^{\circ} \mathrm{C}$; Figure S11. ${ }^{1} \mathrm{H}$ NMR spectra of $(-)-\mathrm{VnD}(\mathrm{A})$ and $\mathrm{PtD}(\mathrm{B})$ in $\mathrm{CDCl}_{3}$ at $25^{\circ} \mathrm{C}$; Figure S12. ${ }^{13} \mathrm{C}$ NMR and DEPT spectra of $(-)-\mathrm{VnD}$ in $\mathrm{CDCl}_{3}$ at $25^{\circ} \mathrm{C}$; Figure $\mathrm{S} 13 .{ }^{1} \mathrm{H}-{ }^{1} \mathrm{H}$ COSY and HMQC spectra of $(-)-\mathrm{VnD}$ in $\mathrm{CDCl}_{3}$ at $25^{\circ} \mathrm{C}$; Figure S14. ${ }^{13} \mathrm{C} \mathrm{NMR}$ and DEPT spectra of PtD in $\mathrm{CDCl}_{3}$ at $25{ }^{\circ} \mathrm{C}$; Figure S15. ${ }^{1} \mathrm{H}_{-}{ }^{1} \mathrm{H}$ COSY and $\mathrm{HMQC}$ spectra of $\mathrm{PtD}$ in $\mathrm{CDCl}_{3}$ at $25^{\circ} \mathrm{C}$; Table S1. Radical copolymerization of terpenoid-derived exo-methylene 6-membered ring conjugated dienes $\left(\mathrm{M}_{1}\right)$ and various common vinyl monomers $\left(\mathrm{M}_{2}\right)$ in toluene at $60{ }^{\circ} \mathrm{C}$.

Author Contributions: Conceptualization, K.S. and M.K.; methodology, T.N., K.S. and M.K.; investigation, T.N., K.S. and M.K., writing—original draft preparation, T.N.; writing—review and editing, K.S. and M.K.; supervision, K.S. and M.K.; project administration, M.K.; funding acquisition, M.K. All authors have read and agreed to the published version of the manuscript.

Funding: This work was supported by JSPS KAKENHI Grant Number JP20H04809 in Hybrid Catalysis for Enabling Molecular Synthesis on Demand, Japan-France Research Cooperative Program between JSPS and CNRS (Grant number JPJSBP120192907), a project (JPNP18016) commissioned by the New Energy and Industrial Technology Development Organization (NEDO), and the Program for Leading Graduate Schools "Integrative Graduate School and Research Program in Green Natural Sciences".

Conflicts of Interest: The authors declare no conflict of interest.

\section{References}

1. Moad, G.; Solomon, D.H. The Chemistry of Radical Polymerization: Second Fully Revised Edition; Elsevier: Oxford, UK, 2006.

2. Hawker, C.J.; Bosman, A.W.; Harth, E. New Polymer Synthesis by Nitroxide Mediated Living Radical Polymerizations. Chem. Rev. 2001, 101, 3661-3688. [CrossRef] [PubMed]

3. Matyjaszewski, K.; Xia, J.H. Atom Transfer Radical Polymerization. Chem. Rev. 2001, 101, 2921-2990. [CrossRef] [PubMed]

4. Kamigaito, M.; Ando, T.; Sawamoto, M. Metal-Catalyzed Living Radical Polymerization. Chem. Rev. 2001, 101, 3689-3745. [CrossRef] [PubMed]

5. Moad, G.; Rizzardo, E.; Thang, S.H. Toward Living Radical Polymerization. Acc. Chem. Res. 2008, 41, 1133-1142. [CrossRef] [PubMed]

6. Matyjaszewski, K. Atom Transfer Radical Polymerization (ATRP): Current Status and Future Perspectives. Macromolecules 2012, 45, 4015-4039. [CrossRef]

7. McKenzie, T.G.; Fu, Q.; Uchiyama, M.; Satoh, K.; Xu, J.; Boyer, C.; Kamigaito, M.; Qiao, G.G. Beyond Traditional RAFT: Alternative Activation of Thiocarbonylthio Compounds for Controlled Polymerization. Adv. Sci. 2016, 3, 1500394. [CrossRef]

8. Ouchi, M.; Sawamoto, M. 50th Anniversary Perspective: Metal-Catalyzed Living Radical Polymerization: Discovery and Perspective. Macromolecules 2017, 50, 2603-2614. [CrossRef]

9. Kamigaito, M.; Sawamoto, M. Synergistic Advances in Living Cationic and Radical Polymerizations. Macromolecules 2020, 53, 6749-6753. [CrossRef] 
10. Nothling, M.D.; Fu, Q.; Reyhani, A.; Allison-Logan, S.; Jung, K.; Zhu, J.; Kamigaito, M.; Boyer, C.; Qiao, G.G. Progress and Perspective Beyond Traditional RAFT Polymerization. Adv. Sci. 2020, 7, 2001656. [CrossRef]

11. Yao, K.; Tang, C. Controlled Polymerization of Next-Generation Renewable Monomers and Beyond. Macromolecules 2013, 46, 1689-1712. [CrossRef]

12. Iwata, T. Biodegradable and Bio-Based Polymers: Future Prospects of Eco-Friendly Plastics. Angew. Chem. Int. Ed. 2015, 54, 3210-3215. [CrossRef] [PubMed]

13. Zhu, Y.; Romain, C.; Williams, C.K. Sustainable polymers from renewable resources. Nature 2016, 540, 354-362. [CrossRef] [PubMed]

14. Froidevaux, V.; Negrell, C.; Caillol, S.; Pascault, J.-P.; Boutevin, B. Biobased Amines: From Synthesis to Polymers; Present and Future. Chem. Rev. 2016, 116, 14181-14224. [CrossRef] [PubMed]

15. Llevot, A.; Dannecker, P.-K.; von Czapiewski, M.; Over, L.C.; Söyer, Z.; Meier, M.A.R. Renewability is not Enough: Recent Advances in the Sustainable Synthesis of Biomass-Derived Monomers and Polymers. Chem. Eur. J. 2016, 22, 11510-11521. [CrossRef]

16. Thomsett, M.R.; Storr, T.E.; Monaghan, O.R.; Stockman, R.A.; Howdle, S.M. Progress in the sustainable polymers from terpenes and terpenoids. Green Mater. 2016, 4, 115-134. [CrossRef]

17. Llevot, A.; Grau, E.; Carlotti, S.; Grelier, S.; Cramail, H. From Lignin-Derived Aromatic Compounds to Novel Biobased Polymers. Macromol. Rapid Commun. 2016, 37, 9-28. [CrossRef]

18. Schneiderman, D.K.; Hillmyer, M.A. There is a Great Future in Sustainable Polymers. Macromolecules 2017, 50, 3733-3749. [CrossRef]

19. Nguyen, H.T.H.; Rostagno, P.; Qi, M.; Feteha, A.; Miller, S.A. The quest for high glass transition temperature bioplastics. J. Mater. Chem. A 2018, 6, 9298-9331. [CrossRef]

20. Tang, X.; Chen, E.Y.-X. Toward Infinity Recyclable Plastics Derived from Renewable Cyclic Esters. Chem 2019, 5, 284-312. [CrossRef]

21. O'Dea, R.M.; Willie, J.A.; Epps, T.H., III. 100th Anniversary of Macromolecular Science Viewpoint: Polymers from Lignocellulosic Biomass. Current Challenges and Future Opportunities. ACS Macro Lett. 2020, 9, 476-493.

22. Erman, W.F. Chemistry of the Monoterpenes: An Encyclopedia Handbook; Marcel Dekker, Inc.: New York, NY, USA, 1985.

23. Connolly, J.D.; Hill, R.A. Dictionary of Terpenoids; Chapman \& Hall: London, UK, 1991.

24. Breitmaier, E. Terpenes: Flavors, Fragrances, Pharmaca, Pheromones; Wiley-VCH: Weinheim, Germany, 2006.

25. Handbook of Essential Oils: Science, Technology, and Applications; Başer, K.H.C.; Buchbouer, G. (Eds.) CRC Press: Boca Baton, FL, USA, 2016.

26. Satoh, K.; Kamigaito, M. New Polymerization Methods for Biobased Polymers. In Bio-Based Polymers; Kimura, Y., Ed.; CMC: Tokyo, Japan, 2013; pp. 95-111.

27. Satoh, K. Controlled/Living Polymerization of renewable vinyl monomers into bio-based polymers. Polym. J. 2015, 47, 527-536. [CrossRef]

28. Kamigaito, M.; Satoh, K. Bio-Based Hydrocarbon Polymers, In Encyclopedia of Polymeric Nanomaterials.; Kobayashi, S., Müllen, K., Eds.; Springer: Heidelberg, Germany, 2015; Volume 1, pp. 109-118.

29. Kamigaito, M.; Satoh, K. Sustainable Vinyl Polymers via Controlled Polymerization of Terpenes. In Sustainable Polymers from Biomass; Tang, C., Ryu, C.Y., Eds.; Wiley-VCH: Weinheim, Germany, 2017; pp. 55-90.

30. Akkapeddi, M.K. Poly $(\alpha$-methylene- $\gamma$-butyrolactone) Synthesis, Configurational Structure, and Properties. Macromolecules 1979, 12, 546-551. [CrossRef]

31. Akkapeddi, M.K. The free radical copolymerization characteristics of $\alpha$-methylene $\gamma$-butyrolactone. Polymer 1979, 20, 1215-1216. [CrossRef]

32. Mosnacek, J.; Matyjaszewski, K. Atom Transfer Radical Polymerization of Tulipalin A: A Naturally Renewable Monomer. Macromolecules 2008, 41, 5509-5511. [CrossRef]

33. Mosnacek, J.; Yoon, J.A.; Juhari, A.; Koynov, K.; Matyjaszewski, K. Synthesis, morphology and mechanical properties of linear triblock copolymers based on poly( $\alpha$-methylene- $\gamma$-butyrolactone). Polymer 2009, 50, 2087-2094. [CrossRef]

34. Zhang, Y.; Miyake, G.M.; Chen, E.Y.-X. Alane-Based Classical and Frustrated Lewis Pairs in Polymer Synthesis: Rapid Polymerization of MMA and Naturally Renewable Methylene Butyrolactones to High Molecular Weight Polymers. Angew. Chem. Int. Ed. 2010, 49, 10158-10162. [CrossRef] 
35. Schmitt, M.; Falivene, L.; Caporaso, L.; Cavallo, L.; Chen, E.Y.-X. High-speed organocatalytic polymerization of a renewable methylene butyrolactone by a phospazene superbase. Polym. Chem. 2014, 5, 3261-3270. [CrossRef]

36. Pfelifer, V.F.; Vojnovich, C.; Heger, E.N. Itaconic Acid by Fermentation with Aspergillus Terreus. Ind. Chem. Eng. 1952, 44, 2975-2980. [CrossRef]

37. Kertes, A.S.; King, C.J. Extraction chemistry of fermentation product carboxylic acids. Biotechnol. Bioeng. 1986, 28, 269-282. [CrossRef]

38. Tate, B.E. Polymerization of itaconic acid and derivatives. Adv. Polym. Sci. 1967, 5, $214-232$.

39. Ishida, S.; Saito, S. Polymerization of Itaconic Acid Derivatives. J. Polym. Sci. Part. A-1 Polym. Chem. 1967, 5, 689-705. [CrossRef]

40. Satoh, K.; Lee, D.-H.; Nagai, K.; Kamigaito, M. Precision Synthesis of Bio-Based Acrylic Thermoplastic Elastomer by RAFT Polymerization of Itaconic Acid Derivatives. Macromol. Rapid Commun. 2014, 35, 161-167. [PubMed]

41. Gowda, R.R.; Chen, E.Y.-X. Synthesis of $\beta$-methyl- $\alpha$-methylene- $\gamma$-butyrolactone from biorenewable itaconic acid. Org. Chem. Fornt. 2014, 1, 230-234. [CrossRef]

42. Nonoyama, Y.; Satoh, K.; Kamigaito, M. Renewable $\beta$-methylstyrenes for bio-based heat-resistant styrenic copolymers: Radical copolymerization enhanced by fluoroalcohol and controlled/living copolymerization by RAFT. Polym. Chem. 2014, 5, 3182-3189.

43. Terao, Y.; Satoh, K.; Kamigaito, M. Controlled Radical Copolymerization of Cinnamic Derivatives as Renewable Vinyl Monomers with Both Acrylic and Styrenic Substituents: Reactivity, Regioselectivity, Properties, and Functions. Biomacromolecules 2019, 20, 192-203. [CrossRef]

44. Terao, Y.; Satoh, K.; Kamigaito, M. 1:3 ABAA sequence-regulated substituted polymethylenes via alternating radical copolymerization of methyl cinnamate and maleic anhydride followed by post-polymerization reactions. Eur. Polym. J. 2019, 120, 109225. [CrossRef]

45. Imada, M.; Takenaka, Y.; Hatanaka, H.; Tsuge, T.; Abe, H. Unique acrylic resins with aromatic side chains by homopolymerization of cinnamic monomers. Commun. Chem. 2019, 2, 109. [CrossRef]

46. Takeshima, H.; Satoh, K.; Kamigaito, M. Bio-Based Functional Styrene Monomers Derived from Naturally Occurring Ferulic Acid for Poly(vinylcatechol) and Poly(vinylguaicol) via Controlled Radical Polymerization. Macromolecules 2017, 50, 4206-4216. [CrossRef]

47. Takeshima, H.; Satoh, K.; Kamigaito, M. Scalable Synthesis of Bio-Based Functional Styrene: Protected Vinyl Catechol from Caffeic Acid and Controlled Radical and Anionic Polymerizations Thereof. ACS Sustainable Chem. Eng. 2018, 6, 13681-13686. [CrossRef]

48. Takeshima, H.; Satoh, K.; Kamigaito, M. Bio-Based Vinylphenol Family: Synthesis via Decarboxylation of Naturally Occurring Cinnamic Acids and Living Radical Polymerization for Functionalized Polystyrenes. J. Polym. Sci. 2020, 58, 91-100. [CrossRef]

49. Satoh, K.; Matsuda, M.; Nagai, K.; Kamigaito, M. AAB-Sequence Living Radical Chain Copolymerization of Naturally-Occurring Limonene with Maleimide: An End-to-End Sequence-Regulated Copolymer. J. Am. Chem. Soc. 2010, 132, 10003-10005. [CrossRef] [PubMed]

50. Matsuda, M.; Satoh, K.; Kamigaito, M. Periodically Functionalized and Grafted Copolymers via 1:2-Sequence-Regulated Radical Copolymerization of Naturally Occurring Functional Limonene and Maleimide Derivatives. Macromolecules 2013, 46, 5473-5482. [CrossRef]

51. Matsuda, M.; Satoh, K.; Kamigaito, M. Controlled Radical Copolymerization of Naturally-Occurring Terpenes with Acrylic Monomers in Fluorinated Alcohol. KGK Kaut. Gummi Kunstst. 2013, 66, 51-56.

52. Matsuda, M.; Satoh, K.; Kamigaito, M. 1:2-Sequence-Regulated Radical Copolymerization of Naturally Occurring Terpenes with Maleimide Derivatives in Fluorinated Alcohol. J. Polym. Sci. Part. A Polym. Chem. 2013, 51, 1774-1785. [CrossRef]

53. Miyaji, H.; Satoh, K.; Kamigaito, M. Bio-Based Polyketones by Selective Ring-Opening Radical Polymerization of $\alpha$-Pinene Derived Pinocarvone. Angew. Chem. Int. Ed. 2016, 55, 1372-1376. [CrossRef]

54. Ojika, M.; Satoh, K.; Kamigaito, M. BAB-random-C Monomer Sequence via Radical Terpolymerization of Limonene (A), Maleimide (B), and Methacrylate (C): Terpene Polymers with Randomly Distributed Periodic Sequences. Angew. Chem. Int. Ed. 2017, 56, 1789-1793. [CrossRef] 
55. Hashimoto, H.; Takeshima, H.; Nagai, T.; Uchiyama, M.; Satoh, K.; Kamigaito, M. Valencene as a naturally occurring sesquiterpene monomer for radical copolymerization with maleimide to induce concurrent 1:1 and 1:2 propagation. Polym. Degrad. Stab. 2019, 161, 183-190. [CrossRef]

56. Runckel, W.J.; Goldblatt, L.A. Inhibition of Myrcene Polymerization during Storage. Ind. Eng. Chem. 1946, 38, 749-751. [CrossRef]

57. Johanson, A.J.; McKennon, F.L.; Goldblatt, L.A. Emulsion Polymerization of Myrcene. Ind. Eng. Chem. 1948, 401, 500-502. [CrossRef]

58. Marvel, C.S.; Hwa, C.C.L. Polymyrcene. J. Polym. Sci. 1960, 45, 25-34. [CrossRef]

59. Cawse, J.L.; Stanford, J.L.; Still, R.H. Polymers from Renewable Resources. III. Hydroxy-Terminated Myrcene Polymers. J. Appl. Polym. Sci. 1986, 31, 1963-1975. [CrossRef]

60. Trumbo, D.L. Free radical copolymerization behavior of myrcene I. Copolymers with styrene, methyl methacrylate or $p$-fluorostyrene. Polym. Bull. 1993, 31, 629-636. [CrossRef]

61. Sarkar, P.; Bhowmick, A.K. Synthesis, characterization and properties of a bio-based elastomer: Polymyrcene. RSC Adv. 2014, 41, 61343-61354. [CrossRef]

62. Hilschmann, J.; Kali, G. Bio-based polymyrcene with highly ordered structure via solvent free controlled radical polymerization. Eur. Polym. J. 2015, 73, 363-373. [CrossRef]

63. Kamigaito, M.; Satoh, K.; Suzuki, S.; Kori, Y.; Eguchi, Y.; Iwasa, K.; Shiroto, H. $\beta$-Phellandrene polymer, production method for same, and molded article. WO 2015/060310 A1; filed 21 October 2014 and issued 30 April 2015,

64. Nishida, T.; Satoh, K.; Nagano, S.; Seki, T.; Tamura, M.; Li, Y.; Tomishige, K.; Kamigaito, M. Biobased Cycloolefin Polymers: Carvone-Derived Cyclic Conjugated Diene with Reactive exo-Methylene Group for Regioselective and Stereospecific Living Cationic Polymerization. ACS Macro Lett. 2020, 9, 1178-1183. [CrossRef]

65. Matsumoto, A.; Yamamoto, D. Radical Copolymerization of N-Phenylmaleimide and Diene Monomers in Competition with Diels-Alder Reaction. J. Polym. Sci., Part. A Polym. Chem. 2016, 54, 3616-3625. [CrossRef]

66. Li, Y.; Padias, A.B.; Hall, H.K. Evidence for 2-Hexene-1,6-diyl Diradicals Accompanying the Concerted Diels-Alder Cycloaddition of Acrylonitrile with Nonpolar 1,3-Dienes. J. Org. Chem. 1993, 58, 7049-7058. [CrossRef]

67. Trumbo, D.L. Synthesis and Polymerization of 1-Methyl-4-isopropenyl-6-methylene-1-cyclohexene. J. Polym. Sci.: Part. A Polym. Chem. 1995, 33, 599-601. [CrossRef]

68. Kobayashi, S.; Lu, C.; Hoye, T.R.; Hillmyer, M.A. Controlled Polymerization of a Cyclic Diene Prepared from the Ring-Closing Metathesis of a Naturally Occurring Monoterpene. J. Am. Chem. Soc. 2009, 131, 7960-7961. [CrossRef]

69. Yamamoto, D.; Matsumoto, A. Controlled Radical Polymerization of 3-Methylenecyclopentene with N-Substituted Maleimides To Yield Highly Alternating and Regiospecific Copolymers. Macromolecules 2013, 46, 9526-9536. [CrossRef]

70. Polymer Handbook, 4th ed.; Brandrup, J.; Immergut, E.H.; Grulke, E.A. (Eds.) John Wiley \& Sons: New York, NY, USA, 1999.

71. Thang, S.H.; Chong, Y.K.; Mayadunne, R.T.A.; Moad, G.; Rizzardo, E. A novel synthesis of functional dithioesters, dithiocarbamates, xanthates, and trithiocarbonates. Tetrahedron Lett. 1999, 40, 2435-2438. [CrossRef]

Publisher's Note: MDPI stays neutral with regard to jurisdictional claims in published maps and institutional affiliations.

(C) 2020 by the authors. Licensee MDPI, Basel, Switzerland. This article is an open access article distributed under the terms and conditions of the Creative Commons Attribution (CC BY) license (http://creativecommons.org/licenses/by/4.0/). 